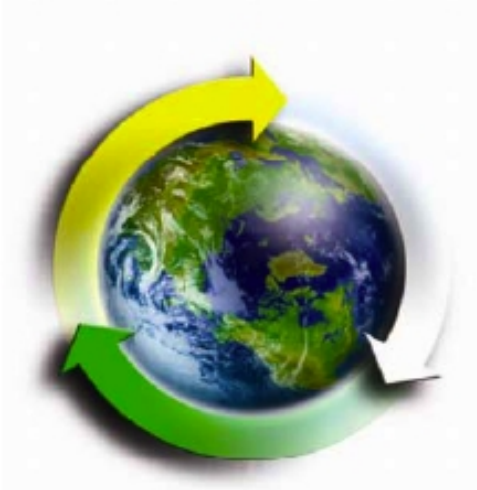

\title{
Assessment of Startup Fuel Options for the GNEP Advanced Burner Reactor (ABR) \\ Global Nuclear Energy Partnership
}

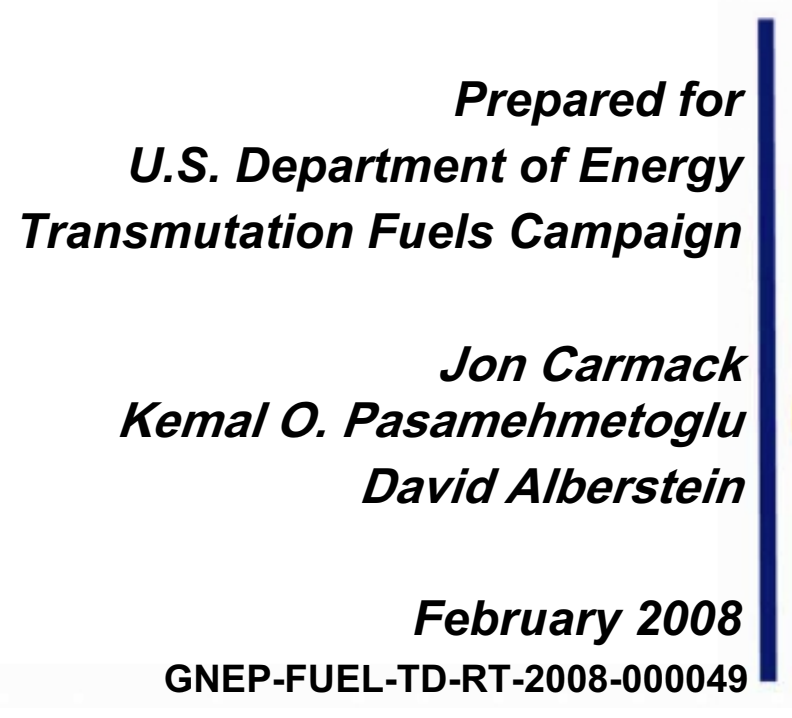


INL/EXT-08-13773

\title{
Assessment of Startup Fuel Options for the GNEP Advanced Burner Reactor (ABR)
}

\author{
Jon Carmack \\ Kemal O. Pasamehmetoglu \\ David Alberstein
}

February 2008

Idaho National Laboratory

Idaho Falls, Idaho 83415

Prepared for the

U.S. Department of Energy

Office of Nuclear Energy

Under DOE Idaho Operations Office

Contract DE-AC07-05ID14517 


\section{DISCLAIMER}

This information was prepared as an account of work sponsored by an agency of the U.S. Government. Neither the U.S. Government nor any agency thereof, nor any of their employees, makes any warranty, expressed or implied, or assumes any legal liability or responsibility for the accuracy, completeness, or usefulness, of any information, apparatus, product, or process disclosed, or represents that its use would not infringe privately owned rights. References herein to any specific commercial product, process, or service by trade name, trade mark, manufacturer, or otherwise, does not necessarily constitute or imply its endorsement, recommendation, or favoring by the U.S. Government or any agency thereof. The views and opinions of authors expressed herein do not necessarily state or reflect those of the U.S. Government or any agency thereof. 
Reviewed by:

Director, Transmutation Fuel Campaign

Transmutation Fuel Campaign Director

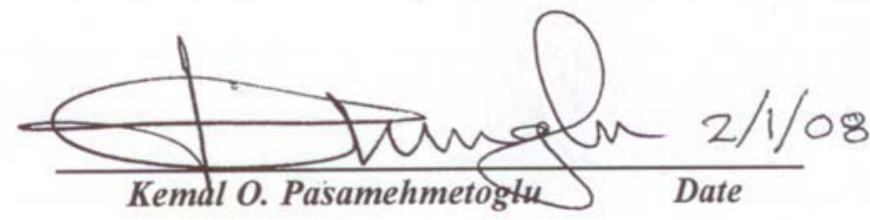

Deputy Director, Transmutation Fuel

Campaign

Transmutation Fuel Campaign Deputy Director

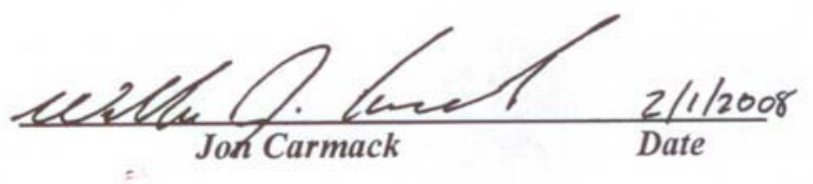


INTENTIONALLY BLANK 


\section{EXECUTIVE SUMMARY}

The Global Nuclear Energy Program (GNEP) includes a program element for the development and construction of an advanced sodium cooled fast reactor to demonstrate the burning (transmutation) of significant quantities of minor actinides obtained from a separations process and fabricated into a transuranic bearing fuel assembly. To demonstrate and qualify transuranic (TRU) fuel in a fast reactor, an Advanced Burner Reactor (ABR) prototype is needed. The ABR would necessarily be started up using conventional metal alloy or oxide ( $\mathrm{U}$ or $\mathrm{U}, \mathrm{Pu}$ ) fuel. Startup fuel is needed for the ABR for the first 2 to 4 core loads of fuel in the ABR. Following start up, a series of advanced TRU bearing fuel assemblies will be irradiated in qualification lead test assemblies in the ABR. There are multiple options for this startup fuel. This report provides a description of the possible startup fuel options as well as possible fabrication alternatives available to the program in the current domestic and international facilities and infrastructure.

Based on preliminary evaluations of technology readiness levels for fast reactor fuels, four candidate fuel forms are identified for ABR startup fuel:

- Mixed uranium-plutonium oxide fuel,

- Enriched uranium-zirconium alloy metal fuel,

- Uranium-Plutonium-Zirconium alloy metal fuel, and

- Enriched uranium oxide fuel.

The fuel options without plutonium require the use of highly-enriched uranium (HEU) unless the ABR core is designed for large power (greater than $1000 \mathrm{MWth}$ ).

Fabrication facilities for supplying the initial core load of startup fuel and $1 / 3$ core replacement per year thereafter are currently not available. We have performed a preliminary evaluation of three different options:

- National Laboratory Capabilities: In FY07, the reactor campaign conducted feasibility studies on fabrication capabilities via the extension of existing facilities at Los Alamos National Laboratory (LANL) for oxide fuel and Idaho National Laboratory (INL) for metal fuel. The results of these studies are summarized (along with preliminary cost estimates) in the attached report. Our initial conclusions are that National Laboratory infrastructure with reasonable extensions may be a feasible option if the ABR core is limited to the lower end of the range considered (approximately $250 \mathrm{MWth}$ or slightly higher).

- Commercial Facilities: An informal evaluation of the available commercial fabrication facilities (Nuclear Fuel Services [NFS] and Babcock and Wilcox Nuclear Operations Group [formerly B\&W NOG]) also is performed using the information available in the literature and through personal communications. It appears that converting one of the commercial facilities to fabricate startup fuel at the required quantities may be feasible. However, the cost, schedule and actual modification requirements for such an option require a more formal evaluation by the commercial sector (which was beyond the scope of the current investigation). Another commercial facility that may be capable of providing fabrication services is the Mixed Oxide Fuel Fabrication Facility (MOX FFF) at the Savannah River Site. This facility is currently under construction, funded by the Surplus Weapons Plutonium Disposition Program. We strongly recommend a formal study of these options in the near future if ABR startup schedule around 2020 is to be maintained. 
- International Facilities: We have also looked at the option of an International supplier for the startup fuel. Even if licensing issues associated with an International supplier can be overcome, at present a readily available International supplier does not exist.

France: France currently has no fast reactor fuel fabrication plant. Because of their timetable for fast deployment of an initial fast reactor in 2020, they are seriously planning for a new facility (mixed oxide plant). A joint design, construction and operation option may be worthwhile to pursue.

Japan: Japan's current fast reactor fabrication plant (mixed oxide) is insufficient to meet their domestic demand for JOYO and MONJU. There are plans for extension of the current plant or for a new plant. A joint design, construction and operation may also be an option.

Russia: The discussions with Russia were not as extensive as with France and Japan. It appears that Russia's large-scale fabrication capabilities are limited to HEU oxide and vibropac fabrication technologies. It is not clear if Russia has any excess capacity to supply fuel to the U.S. To the best of our knowledge, Russia has no large-scale mixed-oxide pellet or metal-slug fabrication capabilities.

On a final note about the startup options, another near-term activity that is highly recommended is to initiate a joint study with Nuclear Regulatory Commission (NRC) on qualification requirements. Even for the conventional fuels, NRC may require additional confirmatory testing. Especially the licensing of various fabrication plant options requires NRC input.

In addition to the above summary, the technical report provides additional information for the different options (including a summary of the FY07 studies for National Laboratory capabilities for fabricating startup fuels). The report also contains information on high-level considerations for the fuel fabrication facility, the standard fabrication processes that must be included within the fabrication facility and some process information regarding the feedstock issues for plutonium-bearing standard fuels. 


\section{CONTENTS}

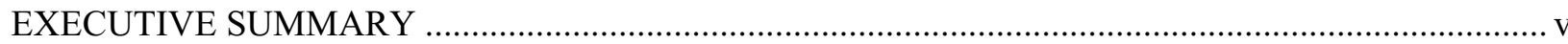

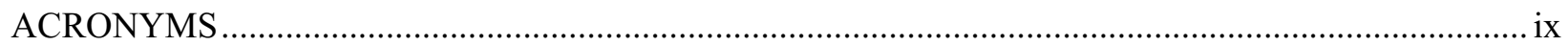

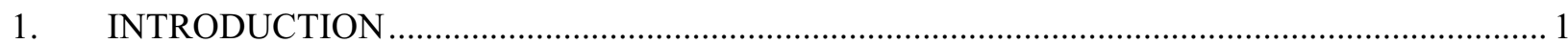

2. HIGH LEVEL CONSIDERATIONS FOR FABRICATION FACILITY ...................................... 4

2.1 Conversion and Pre-Conditioning of WG Pu Feedstock ...................................................... 5

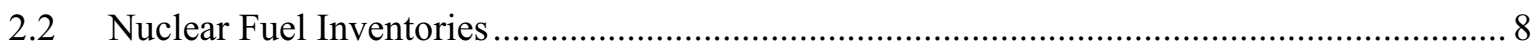

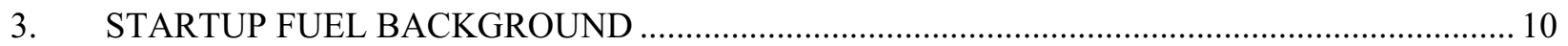

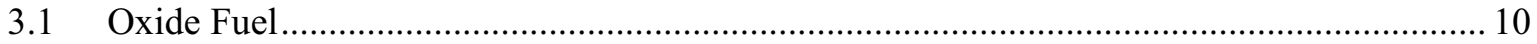

3.1.1 Overview of Oxide Fuel Fabrication Process ......................................................... 10

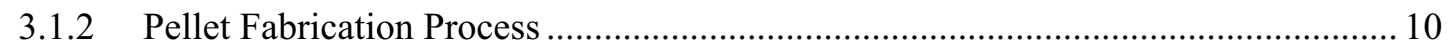

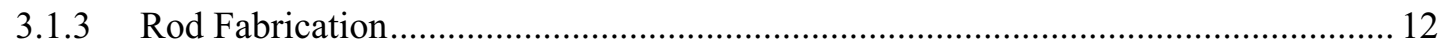

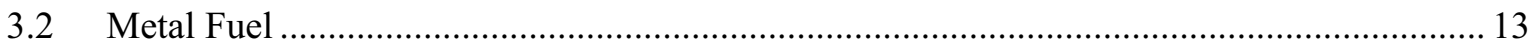

3.2.1 Overview of Metal Alloy Fuel Fabrication Process ................................................. 13

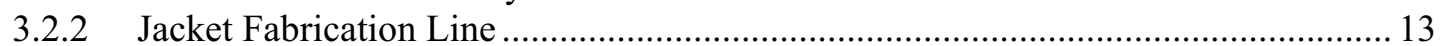

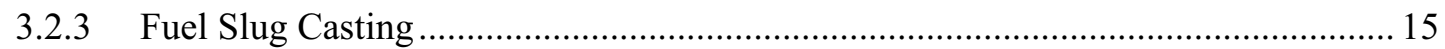

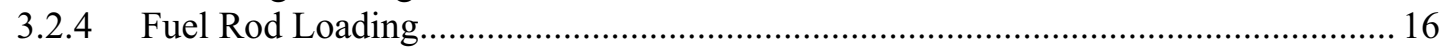

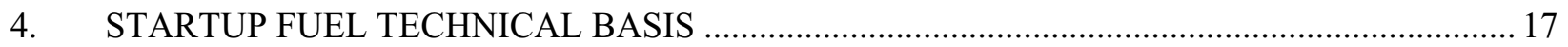

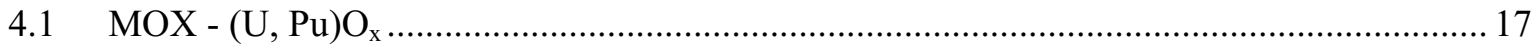

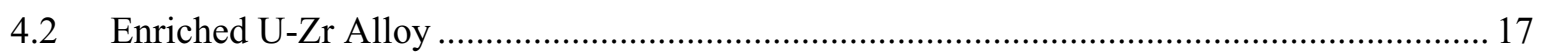

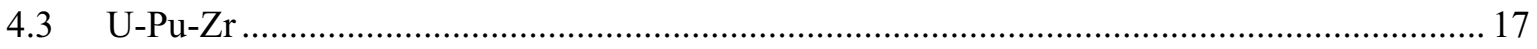

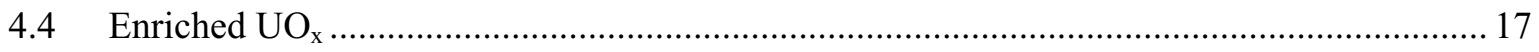

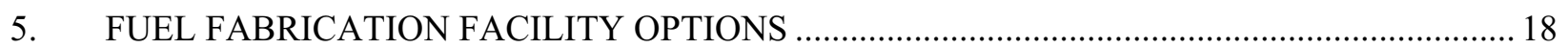

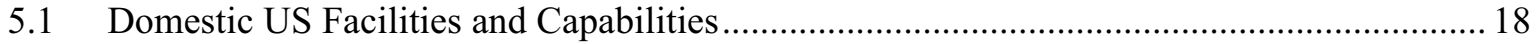

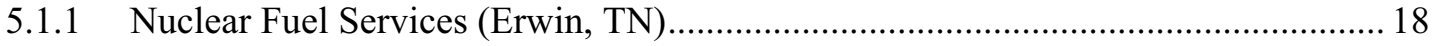

5.1.2 Babcock and Wilcox Nuclear Operations Group (Lynchburg, VA), formerly

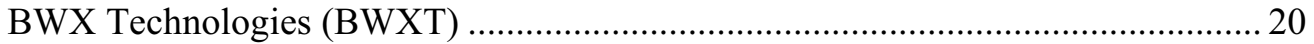

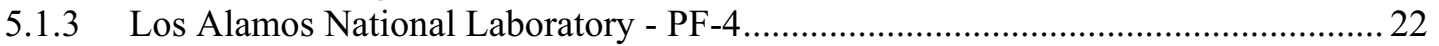

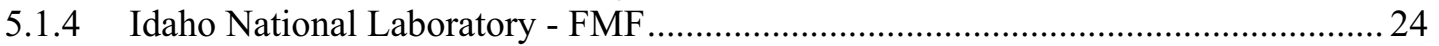

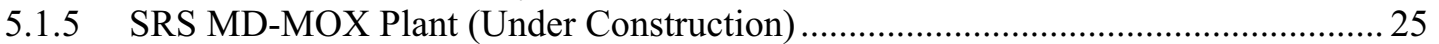

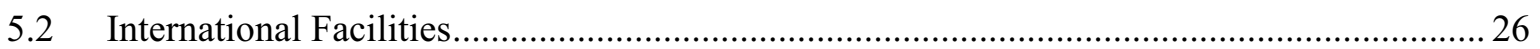

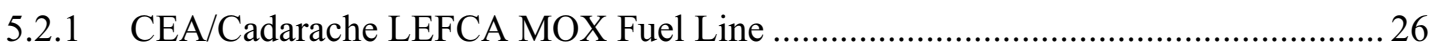

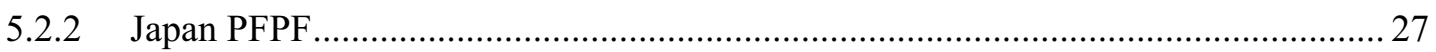

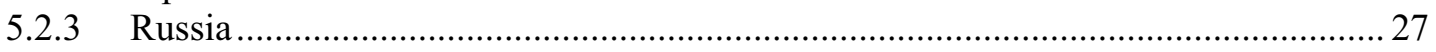

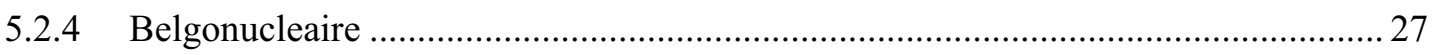

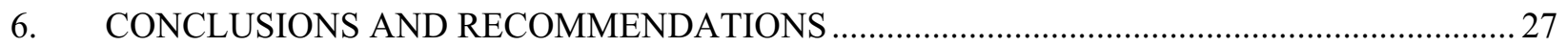

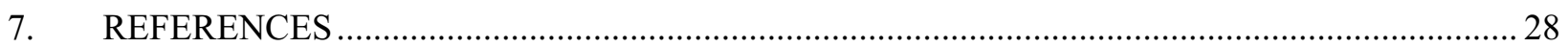




\section{FIGURES}

Figure 1. Generic flowchart of the fuel fabrication process............................................................... 3

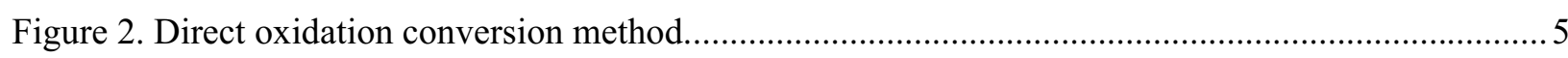

Figure 3. Three-step hydride/nitride conversion process................................................................ 6

Figure 4. Simplified flow diagram of Ga removal aqueous process..................................................... 7

Figure 5. Plutonium inventory in metal fuel processing line ...............................................................

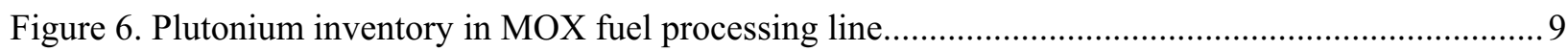

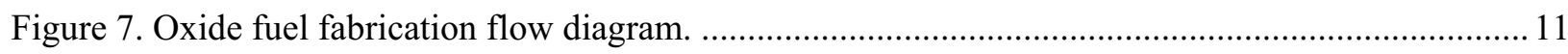

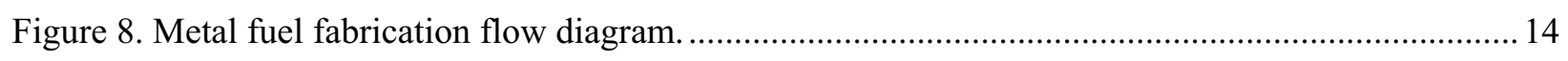

TABLES

Table 1. Required heavy metal for various size startup ABR cores ( $\mathrm{Pu}$ assumes weapons grade

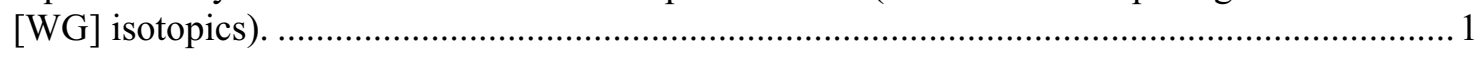

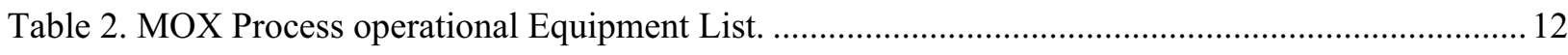

Table 3. Capability Schedule Including MOX Fabrication Startup .....................................................2

Table 4. Summary of potential international startup fuel fabrication facilities. ........................................26 


\section{ACRONYMS}

\begin{tabular}{|c|c|}
\hline ABR & Advanced Burner Reactor \\
\hline ADU & ammonium diuranate \\
\hline AGR & Advanced Gas Reactors \\
\hline ALARA & As Low as Reasonably Achievable \\
\hline ARIES & Advanced Recovery and Integrated Extraction System \\
\hline ATR & Advanced Test Reactor \\
\hline B\&W NOG & Babcock and Wilcox Nuclear Operations Group \\
\hline BWXT & Babcock and Wilcox Technologies \\
\hline $\mathrm{CD}$ & capacitance discharge \\
\hline CEA-LEFCA & $\begin{array}{l}\text { Commissariat a l'Energie Atomique - Laboratory for Study and Experimental } \\
\text { Fabrication of Advanced Fuels }\end{array}$ \\
\hline COGEMA & $\begin{array}{l}\text { Compagnie Generale des Matieres Nucleares (French commercial fuel reprocessing } \\
\text { factory) }\end{array}$ \\
\hline $\mathrm{D} \& \mathrm{D}$ & defueling and decommissioning \\
\hline DOE & Department of Energy \\
\hline DU & depleted uranium \\
\hline EBR-II & Experimental Breeder Reactor II \\
\hline EIS & (Standards) Environmental Information System \\
\hline FCF & Fuel Conditioning Facility \\
\hline FFTF & Fast Flux Test Facility \\
\hline FG & fuel grade \\
\hline FMF & Fuel Manufacturing Facility \\
\hline GNEP & Global Nuclear Energy Program \\
\hline GTAW & gas tungsten arc weld(ing) \\
\hline HEU & highly-enriched uranium \\
\hline HFIR & High-Flux Isotope Reactor \\
\hline $\mathrm{HM}$ & heavy metal \\
\hline IAEA & International Atomic Energy Agency \\
\hline INL & Idaho National Laboratory \\
\hline JAEA & Japan Atomic Energy Agency \\
\hline LANL & Los Alamos National Laboratory \\
\hline LEICA & $\begin{array}{l}\text { Commissariat a l'Energie Atomique - Laboratory for Examination of Irradiated } \\
\text { Advanced Fuels }\end{array}$ \\
\hline $\mathrm{LEUO}_{2}$ & Low-enriched uranium dioxide \\
\hline
\end{tabular}




\begin{tabular}{|c|c|}
\hline LWR & light water reactor \\
\hline MFC & Materials and Fuels Complex \\
\hline MFF & Metal Fuel Tests in FFTF \\
\hline MOX & mixed oxide \\
\hline MOXFFF & Mixed Oxide Fuel Fabrication Facility \\
\hline MT & metric ton \\
\hline NASA & National Aeronautics and Space Administration \\
\hline NFS & Nuclear Fuel Services \\
\hline NNSA & National Nuclear Security Administration \\
\hline NPP & Nuclear Power Plant \\
\hline NRC & Nuclear Regulatory Commission \\
\hline ORNL & Oak Ridge National Laboratory \\
\hline PFF & Plutonium Fabrication Facility \\
\hline PFPF & Plutonium Fuel Production Facility \\
\hline PIDAS & Perimeter Intrusion Detection and Assessment System \\
\hline QC & quality control \\
\hline $\mathrm{R} \& \mathrm{D}$ & Research and Development \\
\hline RG & reactor grade \\
\hline RIAR & Research Institute of Atomic Reactors - Dimitrovgrad, Russia \\
\hline S\&S & Safeguard and Security \\
\hline SEFOR & Southwest Experimental Fast Oxide Reactor \\
\hline SNM & special nuclear material \\
\hline SRS & Savannah River Site \\
\hline TIG & Tungsten Inert Gas \\
\hline TIGR & thermally-induced gallium removal \\
\hline TRU & transuranic \\
\hline UPRR & Uranium Processing and Research Reactor \\
\hline WG & weapons grade \\
\hline ZPPR & Zero Power Plutonium (OR Physics) Reactor \\
\hline
\end{tabular}




\section{ASSESSMENT OF STARTUP FUEL OPTIONS FOR THE GNEP ADVANCED BURNER REACTOR (ABR)}

\section{INTRODUCTION}

This report provides an assessment of the feasible options for the startup core for the first demonstration actinide burning reactor termed the Advanced Burner Reactor (ABR). The first ABR demonstration reactor will require a startup core of qualified nuclear fuel. The only fuels capable of near-term qualification under Nuclear Regulatory Commission rules and requirements are conventional uranium bearing and uranium-plutonium bearing fuels. The following fuel systems have enough irradiation performance history and data as candidates for Nuclear Regulatory Commission (NRC) licensing within a decade:

- $\quad$ Enriched $\left(>20 \% \mathrm{U}^{235}\right) \mathrm{UO}_{\mathrm{x}}$

- Enriched Uranium: $\mathrm{UO}_{\mathrm{x}}$

- Enriched Uranium: U-Zr Alloy

- $\quad$ Mixed oxide $(\mathrm{MOX})$ - $(\mathrm{U}, \mathrm{Pu}) \mathrm{O}_{\mathrm{x}}$ - weapons grade or reactor grade $\mathrm{Pu}$, depleted or natural uranium

- U-Pu-Zr metal alloy - weapons grade or reactor grade $\mathrm{Pu}$, depleted or natural uranium.

Among these options, the choice of driver fuel will depend mainly on the reactor design. However, the availability of feedstock materials and a fabrication facility constraints also must be considered.

Based on the current GNEP program strategy, one of the primary functions of the ABR will be to provide for irradiation of a series of transuranic (TRU) -bearing fuel assemblies for qualification and licensing. Once qualification and licensing of the TRU-bearing fuel assemblies is accomplished, the ABR core will be converted from the conventional startup core assemblies to a full core load of TRU-bearing fuel assemblies. This may be completed in stages over a period of a few years of operation, but the ABR will require approximately 5 to 10 years of conventional fuel assemblies. The number of conventional startup fuel assemblies needed will depend upon the size of the ABR. The size of the ABR is not yet determined and could reasonably range in size between 250 MWth to 2000 MWth based on preliminary design studies conducted by the Reactor Campaign (Chang et al. 2006; Kim et al. 2007; Kim et al. 2008). The required heavy metal (HM) for a core load in the ABR is compared in Table 1.

Table 1. Required heavy metal for various size startup ABR cores (Pu assumes weapons grade [WG] isotopics).

\begin{tabular}{|l|c|c|c|c|c|c|}
\hline & \multicolumn{3}{|c|}{ Metal Core } & \multicolumn{3}{c|}{ Oxide Core } \\
\hline & $250 \mathrm{MWth}$ & $1000 \mathrm{MWth}$ & $2000 \mathrm{MWth}$ & $250 \mathrm{MWth}$ & $1000 \mathrm{MWth}$ & $2000 \mathrm{MWth}$ \\
\hline $\mathrm{U}$ (ton) & 3.7 & 11.1 & 19.3 & 2.9 & 10.9 & 19.7 \\
\hline $\mathrm{Pu}$ (ton) & 0.7 & 2.0 & 3.7 & 0.8 & 2.6 & 4.5 \\
\hline
\end{tabular}

It is envisioned that a facility will be required to provide startup fuel assemblies of "conventional" fast reactor fuel for 5 to 10 years until a full core of TRU fuel is available and licensed for operation. The conventional startup fuel will allow operation of the ABR and allow qualification irradiations of a limited number of TRU fuel qualification assemblies. 
The facility is envisioned to consist of all of the necessary equipment and processing capabilities needed to handle available fuel feedstocks and fabricate full assemblies for reactor loading. This would include: plutonium feed preparation for Pu-based fuels (with or without Ga removal) and at least two assembly lines made up of several inter-connected glove boxes and storage at each step until the fuel pins are assembled. The primary purpose of the glove boxes is to prevent spread of airborne contamination and provide appropriate inert processing environment as needed. Fuel pins will be transferred and stored in the fuel assembly area. The feed stock storage (vaults), pre-processing steps, fuel fabrication processing, post fuel processing inspections of slugs/pellets, physical and chemical analyses, slugs/pellets loading in pin, and fuel bundle assembly will take place in one building. The analytical labs and personnel offices will be in the same building.

The facility will receive oxide/metal feedstocks for processing into oxide/metal fuel. For fuel options containing Pu, Sanzo (2006) provides an initial assessment of the plutonium that is potentially available for use in an ABR as part of the Global Nuclear Energy Partnership (GNEP). Based on the planned schedules for the GNEP facilities, there is no adequate supply of fuel grade (FG) Pu available to be used in ABR (Sanzo 2006) as start up fuel. Therefore, it is anticipated that existing WG Pu will be used in the start up fuel. The WG Pu will need to be processed to remove gallium to the desired level. In addition to gallium, the major differences between grades of plutonium are the concentration of various $\mathrm{Pu}$ isotopes and other transuranics, such as americium. WG Pu contains the highest concentration of Pu-239, followed by FG Pu and finally reactor grade (RG) Pu. The RG-Pu contains higher concentration of radioactive isotopes and therefore requires a greater emphasis on worker protection from radiation fields and contamination control while WG requires the least.

A generic flow chart of the start up fuel fabrication process is presented in Figure 1 (Khericha 2007). Based on engineering judgment and recent experiences in constructing nonreactor nuclear facilities, a 3 to 5 year construction period could be assumed for a new facility. A 2-yr startup period (1-yr for cold startup and 1-yr for hot startup) is assumed. 
Assessment of Startup Fuel Options for the GNEP Advanced Burner Reactor (ABR)

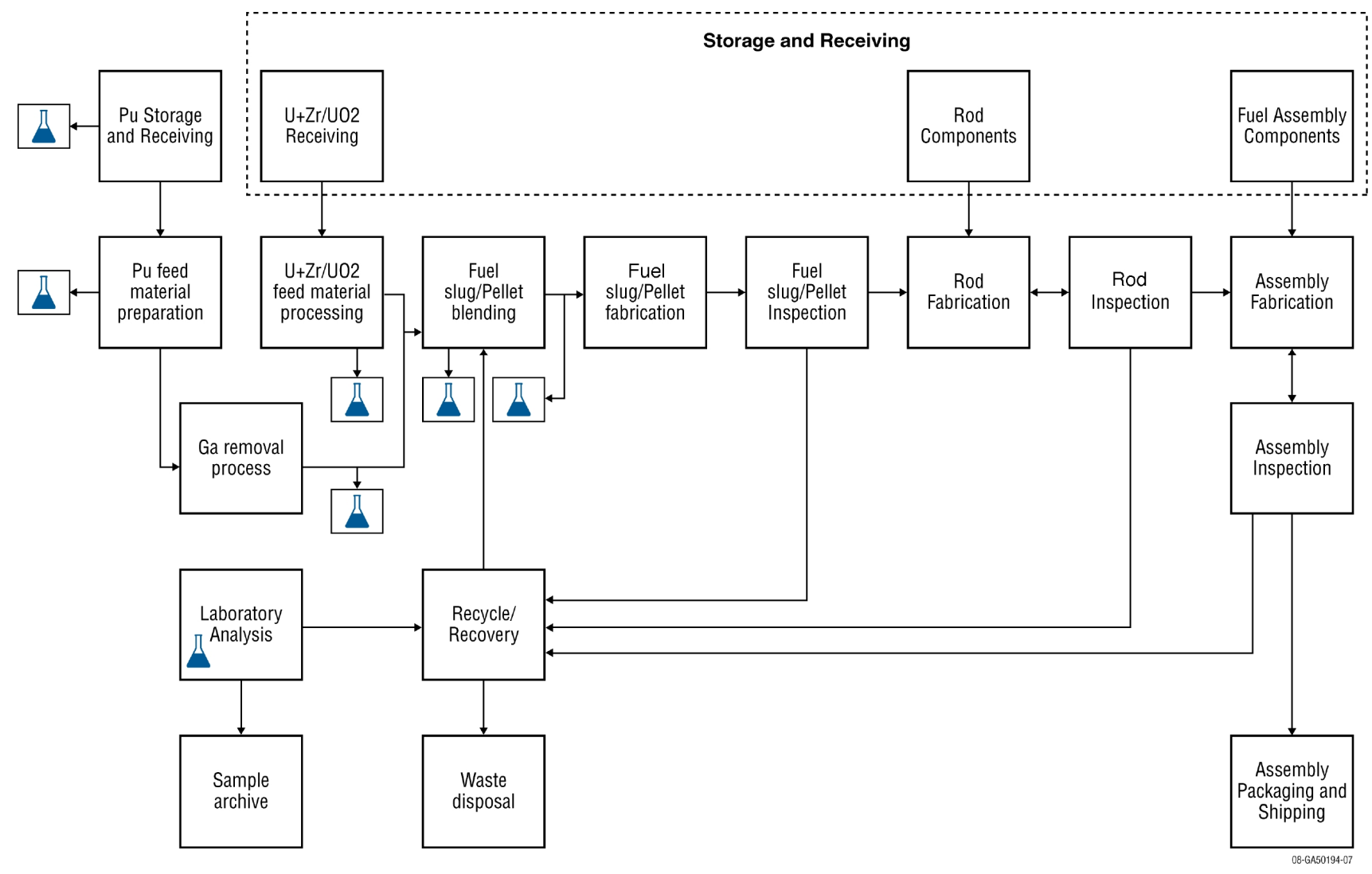

Figure 1. Generic flowchart of the fuel fabrication process. 


\section{HIGH LEVEL CONSIDERATIONS FOR FABRICATION FACILITY}

The purpose of this report is to provide a summary level evaluation of potential options for startup fuel fabrication. As such, the derivation of the detailed requirements for the fabrication facility is outside the scope of the present report. Nonetheless, a high-level review of basic assumptions and issues pertinent to a startup fuel fabrication facility are discussed here as a prevue for subsequent studies if they become necessary. The following have been identified as key issues/assumptions/considerations for early evaluation of a startup fuel fabrication facility. However, considerable additional effort will be needed to develop the requirements for the fabrication facility once the ABR design and implementation strategy mature with time.

- The facility is Safeguard and Security (S\&S) Category 1.

- It may be preferable that the facility be co-located at one of thirteen sites being considered in the ABR Environmental Information System (EIS) and expected to support deployment of the first ABR in the 2020 timeframe.

- The facility will be licensable by the NRC, and will comply with applicable federal, state and local environmental, health and safety requirements.

- The facility will be available for IAEA inspections

- $\quad \mathrm{Pu}$ is assumed to be WG feedstock and will require upfront processing to remove gallium unless fuel irradiation data is available to justify that Ga contamination does not affect fuel performance.

- For Pu bearing fuel options, metal start up fuel compositions are 70/20/10:DU/Pu (WG)/Zr. MOX start up fuel compositions are 63/25/12:DU/Pu (WG)/Oxygen.

- The facility throughput rate depends on the ABR size (number of assemblies for full core), the fuel shelf-life determinations, and the replacement of $1 / 3$ core per year.

- The facility excess capacity is designed to be $20 \%$ higher than the normal yearly throughput requirement.

- Fuel fabrication plant recycle, scrap material and waste may be based on Fuel Conditioning Facility (FCF) and Fuel Manufacturing Facility (FMF) experiences.

- In the case of metal fuel, total $67 \%$ of feed is assumed to be recycled, $4 \%$ goes to recovery and $2 \%$ is waste to be immobilized (based on current assessments).

- In the case of oxide fuel, total $33 \%$ of feed is assumed to be recycled, $4 \%$ goes to recovery and less than $1 \%$ is waste to be immobilized (based on current assessments).

- It is assumed that no more than $4 \mathrm{~kg}$ of $\mathrm{Pu}$ will be processed per batch due to criticality concerns.

- The facility will consist of 2 assembly lines (multiple internally-connected glove boxes in an assembly line); with each line capable of producing $\sim 65$ assemblies/year.

- If $\mathrm{Pu}$ is WG feedstock, the minimum shielding requirement will be needed in the processing line. However, the design may need to consider the use of RG Pu also

- Energy requirements to process the oxide or metal fuel would be roughly the same.

- Fuel hardware other than fuel pellets (MOX) or slugs (metal) such as caps, springs, tubes, etc., are purchased from the off-site qualified suppliers.

- Periodically, the waste will be collected from each assembly line and laboratory, recorded and packed in approved shipping containers (55-gallon drums) on an as-needed basis. The packed containers will be stored at site until shipped to appropriate waste storage depository. 
When specific studies are performed for the DOE sites as potential fuel fabrication centers, references are provided in the appropriate sections. In some cases, referenced data were not available and the values given are estimates based on best engineering judgment. References related to recent European MOX experience, Data Call for Pantex, and Savannah River Site (SRS) MOX fuel lead assembly fabrication facilities, the Idaho National Laboratory (INL) FCF and FMF experiences were reviewed and have been used where applicable. However, much of the detailed information concerning operating European facilities is proprietary and not available.

\subsection{Conversion and Pre-Conditioning of WG Pu Feedstock}

Small amounts of gallium are used as an alloying element in WG plutonium pits. Gallium at such concentrations presents various issues for MOX fuel fabrication and use. Therefore, its concentration must be greatly reduced if the MOX option for plutonium disposition is pursued. At present, based on limited data, the impact of gallium in metallic fuel fabrication and irradiation performance to nominal burnups is minimal, and irradiation performance at high burnup is unknown.

MOX fuel is essentially a ceramic material, prepared by sintering oxides of uranium and plutonium, which are initially both in the form of fine powders. At high concentrations, gallium affects the sintering behavior of the ceramic. In addition, there may be issues with using MOX fuel with excessive gallium concentration as a reactor fuel. While gallium is neutral from neutronic perspective and would not interfere with the chain reaction, gallium oxide can chemically attack zirconium clad (Wilson 1997).

Two approaches for converting plutonium pits into oxide were investigated at Los Alamos and Lawrence Livermore National Laboratories (Kolman 2000). One approach, as shown in Figure 2, is that plutonium metal is converted directly into oxide at $600^{\circ} \mathrm{C}$. Another process, as shown in Figure 3, would convert plutonium metal into a hydride, the hydride into a nitride $(\mathrm{PuN})$, and then to an oxide. As compared to the three-step process, the direct metal oxidation method produces a more coarse powder, having less surface area per gram. After either process, gallium is carried forward in oxide form, $\mathrm{Ga}_{2} \mathrm{O}_{3}$. (To remove hydrogen and provide a metal product, the hydride is simply heated to drive off hydrogen, leaving a plutonium metal ingot.) These approaches are part of the Advanced Recovery and Integrated Extraction System (ARIES) process for pit disassembly and conversion. In each case, the gallium would need to be removed after plutonium oxide has been made, and the plutonium oxide would need to be conditioned to provide the desired powder morphology. The current reference conversion process in the Surplus Weapons Plutonium Disposition Program is direct metal oxidation, which was chosen over the three-step hydride process due to safety concerns associated with free hydrogen in the three-step process.

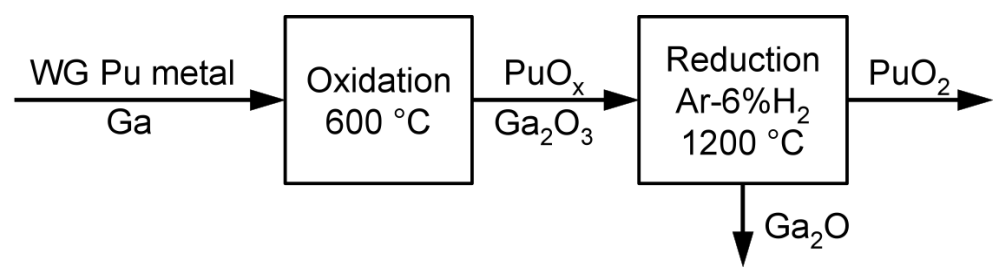

Figure 2. Direct oxidation conversion method. 


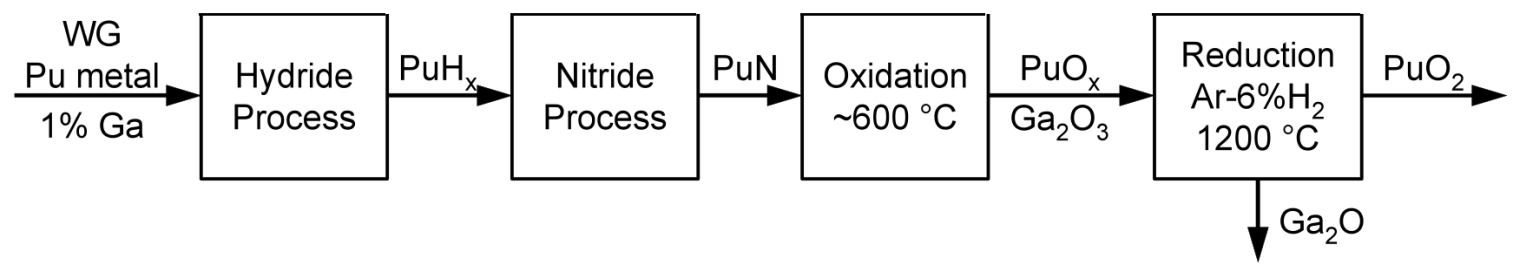

Figure 3. Three-step hydride/nitride conversion process.

There are two processes that have been evaluated to remove gallium from plutonium oxide: an aqueous process and a dry process. Figure 3 shows gallium removal via the dry process. The aqueous process is a fully developed technology for gallium removal and plutonium oxide production, but it results in the generation of large quantities of liquid radioactive wastes. For this reason, efforts were made in the Surplus Weapons Plutonium Disposition Program to avoid using the aqueous process and instead use the dry processes being developed at the Los Alamos and Livermore National Laboratories (Kolman 2000; Bluhm 2004). However, this startup fuel assessment document includes the resource needs and waste stream based on the aqueous process.

The aqueous process is based on dissolution, purification via solvent extraction or ion exchange, and solidification of purified Pu product (Oak Ridge National Laboratory [ORNL] 1998; DeMuth 1997). The solvent extraction process is the reference process used in the MOX Fuel Fabrication Facility (MOXFFF) at SRS, which is currently under construction for the Surplus Weapons Plutonium Disposition Program.

The configuration used for this process includes:

- dissolution of Pu in nitric acid/hydrogen-fluoride or Pu-oxide in nitric acid (electrolytic dissolution with silver as a catalyst)

- purification via solvent extraction or ion exchange

- plutonium (IV) oxalate precipitation at approximately 65 degrees Celsius to help ensure proper oxide-powder morphology and to complete the purification efforts

- calcination in a furnace using rigorously blending in a blender.

A generic aqueous gallium removal process flow diagram is shown in Figure 4. 


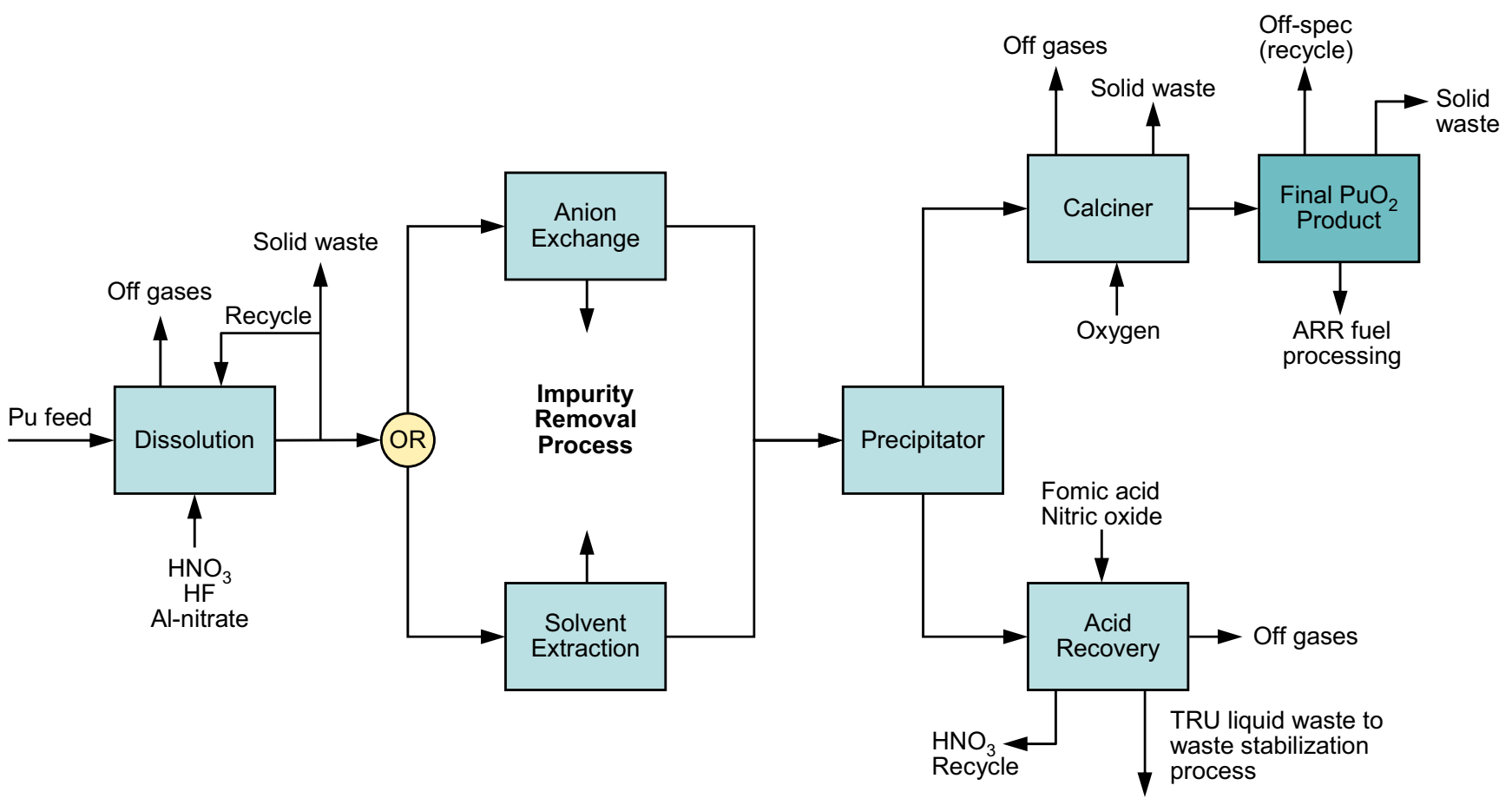

Figure 4. Simplified flow diagram of Ga removal aqueous process. 
In the dry process, the gallium is driven out by reduction and conversion to a sub-oxide form $\left(\mathrm{Ga}_{2} \mathrm{O}\right)$ in an atmosphere of argon with 6 percent hydrogen (Kolman 2000). The sub-oxide of gallium rapidly volatilizes from the plutonium-gallium mix at $1200^{\circ} \mathrm{C}$. This process, also known as thermally-induced gallium removal (TIGR) which has been tested at the laboratory scale, gets gallium down to $\sim 30$ parts per million. In the Surplus Plutonium Disposition Program, this residual plutonium concentration was judged to be too high for use in fabrication of MOX fuel for use in light water reactors. Accordingly, development of the TIGR process was ended, and the aqueous process was chosen as the reference process for the program. The specified gallium content for plutonium oxide feed material was set at 20 parts per billion.

In the U.S., MOX fuel containing 1-5 ppm Ga that was manufactured by Los Alamos National Laboratory (LANL) using the TIGR process was irradiated in the Advanced Test Reactor (ATR) at Idaho National Laboratory at various burnup levels, from 8 to $52 \mathrm{GWd} / \mathrm{MT}(<1$ to $>5$ atom \%). It was concluded that any migration of gallium from fuel to the zircalloy cladding was insignificant and presents no credible threat to the cladding integrity (Hodge 2006; Ott 2005). However, the ATR is a thermal reactor and fuel burnup in the ABR is expected to exceed those to which these tests have been subjected.

ABR fuel cladding will be stainless steel or an advanced stainless steel such as HT-9. Presently, it is not known whether and to what degree gallium-cladding interaction will occur with these cladding materials. In mid-1994, five fuel elements (U-19.8\%Pu-10 Zr-0.2 Ga) made from WG Pu (1\% Ga) were irradiated in Experimental Breeder Reactor II (EBR-II) before it was shut down. These elements achieved a peak burnup of only 1.5 atom \%. To date, no post-irradiation examination has been done on these elements. At the Global ' 07 conference, the Russians noted irradiation testing in BOR-60 of stainless steel-clad oxide fuel containing $100 \mathrm{ppm}$ with no adverse effects. Therefore, no significant amount of data or experience exists at present on irradiation of high Pu-enriched MOX or metallic fuel manufactured from WG feedstock, where gallium is present as impurity, in fast reactor environment. Further evaluation of the potential for gallium-stainless steel cladding interaction will be needed to determine the specification for gallium content in plutonium oxide feed material for use in fast reactor fuel fabrication.

\subsection{Nuclear Fuel Inventories}

As an initial evaluation, a facility that will manufacture 120 assemblies per year is considered. In the case of oxide or metal fuel, total throughput of $\mathrm{Pu}$ is estimated to be 1.4 MT per year. The total throughput of depleted uranium (DU) is estimated to be 3.63 and 5.08 MT for oxide and metal fuel, respectively. It is assumed that no more than $4 \mathrm{~kg}$ of $\mathrm{Pu}$ will be used per batch due to criticality concern. A $4 \mathrm{~kg} \mathrm{Pu}$ feed rate will result in a maximum of less than $7 \mathrm{~kg}$ of $\mathrm{Pu}$ in the process at any time. Figure 5 and Figure 6 show the plutonium mass balance for the metal and MOX fuel processes, respectively.

Most of the plutonium inventories will be in the form of fuel assemblies and feedstock. To minimize Pu inventory at the site, two shipments of fuel assemblies per year and two shipments of feed stock per year are assumed. This results in the total Pu inventory of at the site being 1.5 MT in the fabrication facility. Assuming 50\% contingency, the total Pu inventory in the fuel fabrication facility would be $2.2 \mathrm{MT}$. 


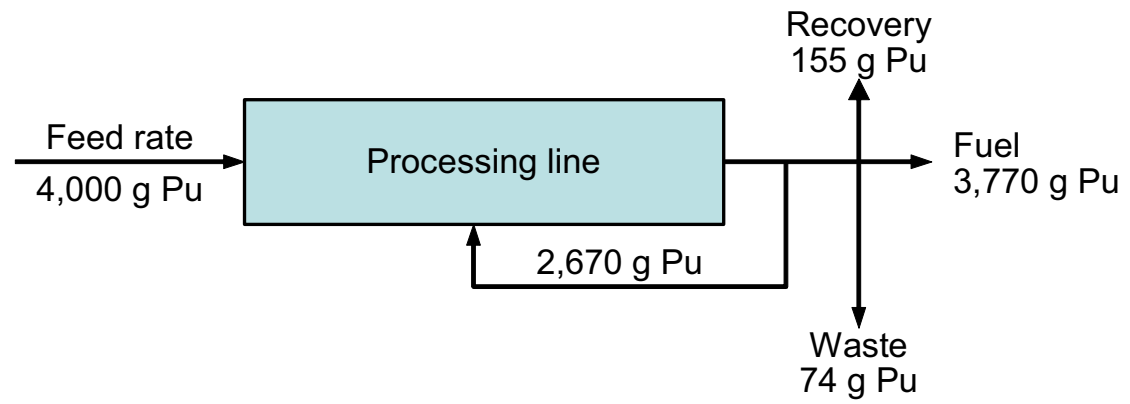

Figure 5. Plutonium inventory in metal fuel processing line.

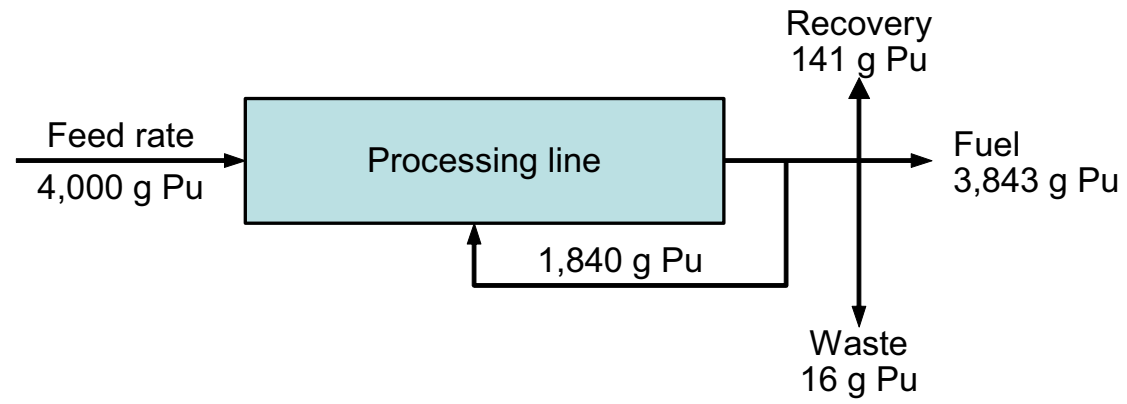

Figure 6. Plutonium inventory in MOX fuel processing line. 


\section{STARTUP FUEL BACKGROUND}

In this section, a general overview of the fabrication processes that would be deployed in the startup fuel fabrication facility are provided.

\subsection{Oxide Fuel}

\subsubsection{Overview of Oxide Fuel Fabrication Process}

MOX fuel rod fabrication process is derived from the processes used to fabricate fuel for light water (thermal) reactor in Europe. The process for fabrication of MOX fuel rods for fast reactors, such as the $\mathrm{ABR}$, is expected to be similar. Anticipated differences are discussed in the descriptions below. The general MOX fuel rod fabrication process is illustrated in Figure 7, and more detailed descriptions are provided following the figure. This description is not meant to be all-inclusive, but is representative of the scope of work associated with the fabrication processes.

\subsubsection{Pellet Fabrication Process}

\subsubsection{Plutonium/Uranium Oxide Feed}

Plutonium and uranium oxide feed material is required to meet rigorous specifications for isotopic vector, impurity content, particle size distribution, and residual moisture. The feedstock can include scrap material from previous runs, which is considered to improve the final product.

\subsubsection{Primary Blend}

In the primary blend step, the plutonium oxide, uranium oxide, and scrap feed materials are initially blended. The feedstock is poured into a blending jar, and milling media may be added to enhance particle size requirements. During this operation, binders and pore formers may also be added. The primary blend step typically produces $20-30 \mathrm{wt} \% \mathrm{PuO}_{2}$ blended powder that is intimately mixed, with a fine particle size.

\subsubsection{Secondary Blend}

In the secondary blend operation, another blender jar is filled with primary blend and additional uranium oxide, then run on a Turbula ${ }^{\circledR}$ blender. The secondary blend step may not be required for the fast reactor MOX fuel with 20-30\% plutonium.

\subsubsection{Pellet Pressing}

The blend jar is connected to the pellet press sieve, and the blend is sieved and transferred to the press feed hopper. Pellets are pressed using a hydraulic press that can press one or more pellets simultaneously. The pellets are then placed on the sintering boats and stored.

\subsubsection{Pellet Sintering}

The sintering boats containing green pellets are removed from the green pellet storage glove box and are loaded into the sintering furnace. The furnace operates as a batch process at a specified rate, resulting in a time-temperature sintering profile that meets specified requirements. 


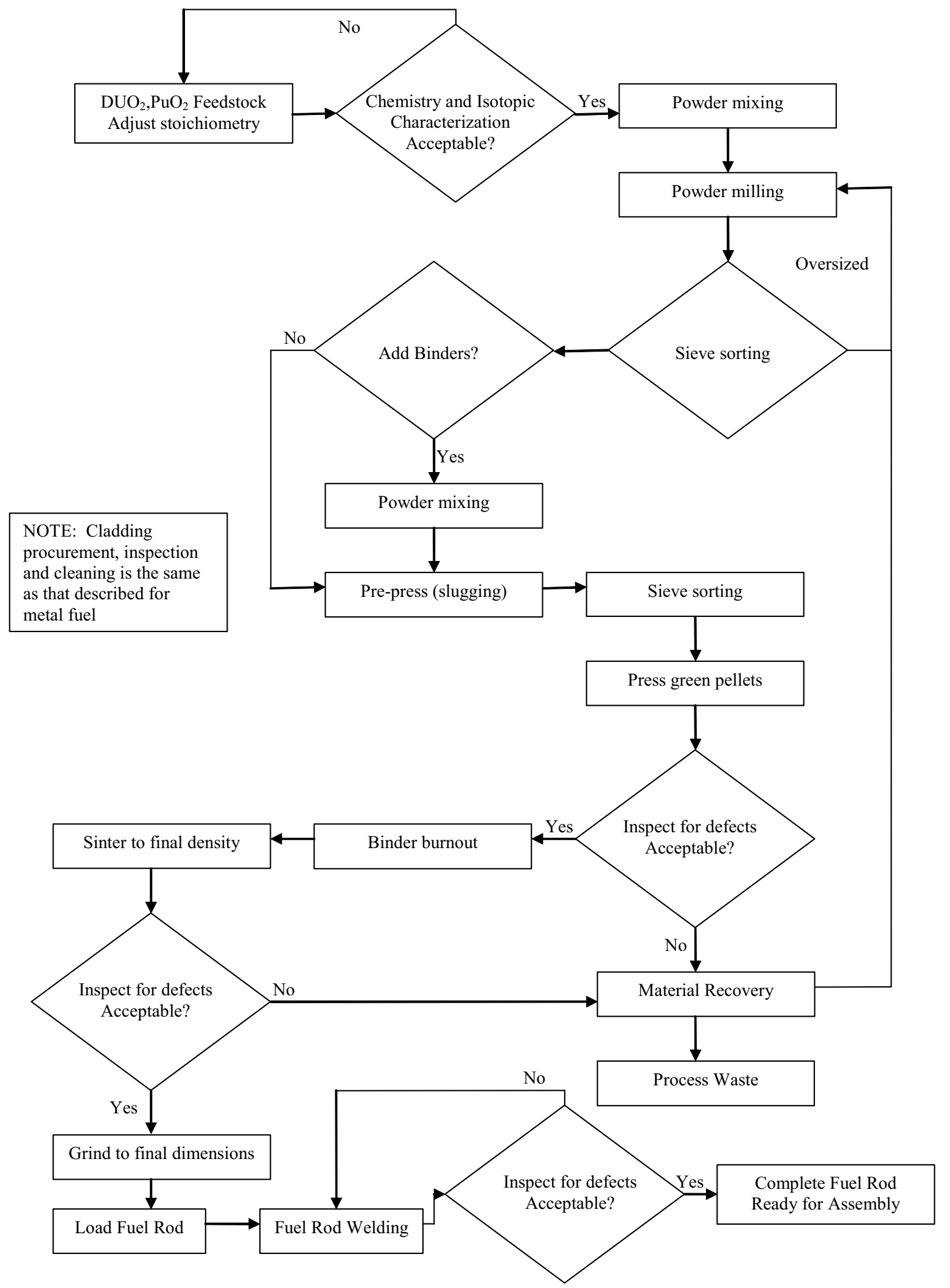

Figure 7. Oxide fuel fabrication flow diagram.

$\left(\mathrm{DUO}_{2}=\right.$ Depleted Uranium Oxide $)$ 


\subsubsection{Pellet Grinding and Inspection/Sorting}

The pellets are placed in a grinder feed hopper and processed through a centerless grinder to obtain the required diameter. Pellet diameter is confirmed during the grinding process using a laser micrometer. These pellets are further inspected according to the specification and sorted, with scrap pellets segregated.

\subsubsection{Scrap Recycle}

Rejected pellets are collected in a crusher box. After collecting a sufficient quantity, a jaw crusher reduces them to a suitable particle size. This material can become part of the feed for future fuel pellets.

\subsubsection{Rod Fabrication}

\subsubsection{Column Preparation}

The sorted pellets are set for the column length needed for one fuel rod. The fuel rod subassembly (fuel rod cladding with its bottom end cap pre-welded into place) is slid through a hood enclosure at the end of the fuel rod fabrication glove box and into the purge chamber.

\subsubsection{Rod Load and Weld}

The fuel pellet column is loaded into the fuel rod cladding. After decontaminating the rod, spring and end cap are installed. The assembled fuel rod is slid into the welding compartment, where the end cap is permanently welded into place using a rotary TIG (Tungsten Inert Gas) welder.

\subsubsection{Rod Inspection}

Following seal weld inspection and verification that decontamination requirements are met, the fuel rod assembly is slid back through the welding compartment and out of the hood enclosure. The fuel rod is then inspected by X-ray techniques for welds and gamma scanned to verify pellet plutonium concentration.

A wire wrap is not added to the oxide rods until assembly fabrication. Table 2 lists, by process, the major pieces of equipment needed for MOX fuel production.

Table 2. MOX Process operational Equipment List.

\begin{tabular}{|c|c|c|}
\hline Process & Equipment & Comment \\
\hline Batching & Balance & $\begin{array}{l}\text { Needed throughput processing line for } \\
\text { nuclear material accountability. }\end{array}$ \\
\hline Blending & Blend Jar & Needed for blending and storage. \\
\hline Milling & Attrition Mill & Continuous feed. \\
\hline Pressing & Automatic Hydraulic Press & Multiple die set for throughput. \\
\hline Sintering & Resistance Furnace & Batch furnace. \\
\hline Grinding & Centerless Grinder & Automatic feed. \\
\hline Pin Welding & Orbital TIG Welder & Identical cold and hot setup. \\
\hline $\mathrm{O} / \mathrm{M}$ Analysis & Furnace w/hygrometer & In-line measurement capability. \\
\hline Dimensions & Digital Indicator, Laser Micrometer & Length, radius, chamfer, dish \\
\hline Gamma Scan & X-ray Radiography & Electronic real-time radiography. \\
\hline
\end{tabular}




\subsection{Metal Fuel}

\subsubsection{Overview of Metal Alloy Fuel Fabrication Process}

The metal fuel fabrication process involves three main parts: jacket fabrication, fuel slug casting, and fuel rod loading. Jacket hardware can be commercially procured, then inspected at the fabrication facility. Jacket fabrication proceeds with a bottom endplug being welded to the jacket, the spacer wire wrap attached, and sodium loaded into the inspected jacket. After sodium loading, the jackets are dimensionally characterized then proceed to fuel rod fabrication. Fuel slugs are injection cast using an induction-heated furnace and cut to length in an argon atmosphere glove box. The fuel rods are then loaded with the fuel, settled into the bond sodium, and seal welded in a clean section of an argon atmosphere glove box and then removed for bonding. Figure 8 shows the main process flow steps for fuel slug casting and fuel rod loading.

The glove box atmosphere for various fabrication steps is a purified inert atmosphere to prevent pyrophoric reaction, but more practically it helps maintain purity of the sodium and fuel inside the fuel rod, which might otherwise decrease with oxygen or moisture content due to reaction products on the surface of the sodium material or fuel slugs. The impact of additional oxygen impurities on fuel performance is not fully evaluated, and subsequent work may suggest that impurity tolerances in the fabrication atmosphere can be relaxed.

The following describes the equipment required for the fabrication process (Hill 2006):

\subsubsection{Jacket Fabrication Line}

\subsubsection{Cladding Tubes and Other Fuel Rod Hardware}

Fuel rod hardware will be commercially procured, as may the assembly of the components into fuel rod jackets and end plugs. The operation at the fuel fabrication facility may only require that the top end plug be welded to the jacket to seal in the fuel, and perhaps attach a wire wrap to the exterior of the cladding. EBR-II experience has shown this to be an acceptable manner to obtain material. All cladding tubes and fuel jackets will be inspected to verify conformance to the specification. It is anticipated that the specifications will be similar to those used previously for EBR-II cladding procurement. Other hardware or materials to be used for hardware fabrication on-site will follow a similar process.

\subsubsection{Bottom End Plug Welding}

The number and quality of bottom jacket welds necessitates an automated or semi-automated welding process be used to obtain a sufficiently low rejection rate. Orbital Gas Tungsten Arc Welding (GTAW) will be used. This method of welding has been used for fuel fabrication previously and is widely used in the pipe and tube welding industry. This system can be commercially procured and then qualified for use on these welds.

\subsubsection{Wire Wrap}

The ABR design uses a wire wrap as employed in previous fast reactor fuel fabrication campaigns. Little developmental work will be required because a system has been built and used in the past. A similar system will be assembled to weld the bottom of the wire in place, wrap the wire around the jacket, then weld the top wire end in place. 


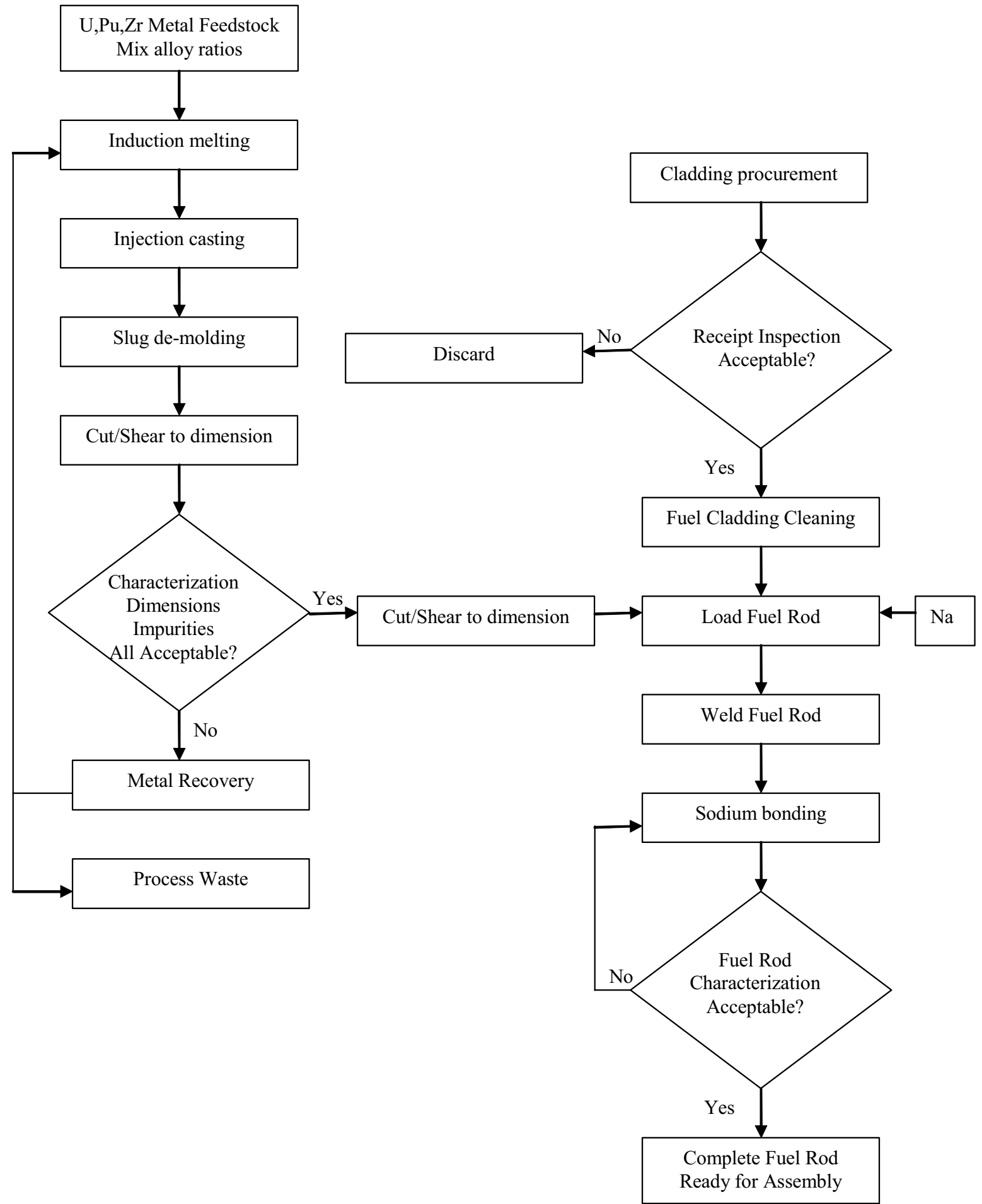

Figure 8. Metal fuel fabrication flow diagram. 


\subsubsection{Jacket Characterization}

The completed jackets will be dimensionally characterized. The number of fuel rods to be fabricated makes desirable use of semi-automated instruments such as laser micrometers, profilometers, air gauges, etc. End-plug welds will undergo radiographic inspection as well as leak testing.

\subsubsection{Sodium Extrusion Press}

Metal fuel swells upon irradiation, therefore a gap between the fuel and cladding to accommodate this swelling is built into the fuel rod. In order to increase heat transfer from the fuel to the cladding, this gap must be filled with a substance with a high thermal conductivity. Because metal fuel is compatible with sodium coolant in fast reactors, it was decided that the best heat conduction medium was sodium. It is critical to keep jacket welding surfaces free of sodium, therefore sodium needs to be placed in the jacket in solid form before the slugs are loaded. Past experience has shown it is easiest to do this by cold extruding a sodium wire using a sodium extrusion press. The wire should have a diameter small enough so that it will easily drop into the jacket. Sodium is easily deformed at room temperature and therefore the press should be easily fabricated. Drawings of past presses exist and can be used to assemble additional presses.

\subsubsection{Sodium Loading Glove Box}

Sodium is a reactive alkali metal that therefore must be handled in an inert atmosphere glove box. Operating parameters of the glove box should be set to maintain a moisture and oxygen content of $<50 \mathrm{ppm}$. However, it is not necessary to maintain levels lower than $25 \mathrm{ppm}$ because too pure an atmosphere increases the difficulty in working with the sodium because of stickiness.

\subsubsection{Fuel Slug Casting}

\subsubsection{Casting Furnace}

The casting furnace will need to be constructed for plutonium containment and of a suitable size to cast at least tens of slugs per batch. The furnace will be capable of homogenizing the alloy melt and injection casting in one operation. The furnace will be of the induction type and will heat the melt under vacuum to facilitate injection casting as well as to preclude any reactions with the atmosphere. After sufficient heating and homogenization, quartz glass molds will be lowered into the melt, and the furnace will be pressurized to force the melt into the molds. This furnace will be modeled after existing casting furnace designs that were used in the FMF to produce fuel for EBR-II.

\subsubsection{Slug Mold Removal}

Initially, single-use quartz glass molds will be used for injection casting. Mold removal will be accomplished by thoroughly breaking the molds and removing the slugs. After slug removal, the glass shards and residual fuel scrap will be separated by physically separating larger pieces and electromagnetically separating fines.

\subsubsection{Slug Trimming}

$\mathrm{U}-\mathrm{Pu}-\mathrm{Zr}$ alloy is a brittle alloy, and fuel slugs can be trimmed in a number of ways. Traditional shearing, sawing, or striking with a hard chisel all have been shown to produce acceptable results. Slug trimmings as well as sacrificial slugs will be used for alloy microstructural and chemical characterization. Trimmings not needed for characterization will be recycled back into the casting process. 


\subsubsection{Slug Dimensional Characterization}

Because this work will be done in a glove box with tens of slugs per batch, it is preferred to use as many semi-automated quality control (QC) instruments as possible. Such instrumentation will include laser micrometers, profilometers, air gauges, etc. All slugs will be individually weighed. All instrument outputs will be automatically recorded and tracked using computer software. This will not only diminish operator fatigue and error but also be amenable to data trending.

\subsubsection{Casting Glove Box}

The casting glove box will be an inert atmosphere glove box designed and approved for plutonium use. All pressure control systems will be at least tertiary. Oxygen and moisture impurities must be maintained to $<50 \mathrm{ppm}$ levels, and other impurities such as nitrogen should also be monitored if feasible. The glove box should be large enough for crucible loading, casting, trimming, QC, crucible coating, and casting alloy heel size reduction for recycle. The metal fuel is a reactive metal and therefore will react with oxygen and oxidize, and fine powders which may be produced through the demolding and shearing process are pyrophoric. This is also the case with the oxide fuels; the $(\mathrm{U}, \mathrm{Pu}) \mathrm{O}_{2}$ will rapidly oxidize to a higher oxide if left in an oxygen-rich atmosphere. In the case of the casting furnace or the sintering furnace, both will need atmospheric control, since the rate of oxidation, and hence heat production increases at higher temperatures.

\subsubsection{Fuel Rod Loading}

\subsubsection{Sodium Settling Furnace}

Bond sodium is settled into the fuel/cladding gap by heating the loaded fuel pin to approximately $150^{\circ} \mathrm{C}$ and holding for 15 minutes. The furnace should be a multi-zone resistively heated furnace long enough to cover the fuel and plenum zone. This furnace will be installed in the fuel rod fabrication glove box and therefore must be designed to run in inert atmospheres of argon, helium, or a mixture of argon and helium.

\subsubsection{Closure Welding}

The closure weld, at the upper end plug, has the same requirements as the bottom jacket weld. The system should be at a minimum semi-automatic and produce reproducible high-quality welds. Two systems are currently under consideration: a capacitance discharge (CD) type or an orbital GTAW. Both have been shown to be feasible through past fabrication experience, and both meet the requirements. Earlier EBR-II fuel fabrication experience relied on CD welding, The CD system uses simpler machinery with fewer parts than orbital welding, which leads to easier maintenance. However, orbital welding is used throughout the welding industry, and many standard systems which could be used inside a glove box can be purchased "off the shelf."

\subsubsection{Fuel Rod Fabrication Glove Box}

Fuel loading of the jacket, slug settling, and closure welding will take place in the fuel rod fabrication glove box. This glove box will be a purified inert atmosphere glove box capable of running in argon, helium, or a mixture of the two. The box should have two separate bays separated by a bulkhead. Fuel slugs will be exposed on one side and loaded into the jacket through a feed-through in the other side. This will keep the external surfaces of the rods free of contamination. 


\subsubsection{Fuel Rod Characterization and Quality Control}

The completed rods will be dimensionally characterized. Semi-automated instruments, such as laser micrometers and profilometers will be used because of numbers of rods to be fabricated. All welds will undergo radiographic inspection as well as leak testing.

\section{STARTUP FUEL TECHNICAL BASIS}

The identified startup fuel options for the Advanced Burner Reactor are dependent upon a number of factors including the use and availability of $\mathrm{Pu}$ and $\mathrm{U}$ feedstock supply and the availability of a fabrication facility capable of supporting the fabrication.

This section discusses the primary advantages and disadvantages of fuel type and isotopic vector selection. Sections 4.1 through 4.5 are provided in prioritized order of the authors' assessment of the fabrication availability and feasibility of fuel supply options.

\subsection{MOX - (U, Pu) $O_{x}$}

Conventional fast reactor mixed oxide fuel is the standard startup fuel for many of the fast reactors in operation today. In addition, it was used to fuel the Fast Flux Test Facility for many years of operation. It has a proven safety basis and fabrication history. The key issue with the use of this fuel for the startup fuel of the ABR is that most of the historical basis for MOX is using the RG isotopic feed stream. Domestic acquisition of a MOX startup fuel would most certainly require the use of WG feedstocks.

\subsection{Enriched U-Zr Alloy}

Similar to the use of a highly-enriched uranium (HEU) oxide core, a HEU U-Zr alloy (binary) metal fuel core could be used as startup fuel. The experience database from the use of this fuel as EBR-II driver fuel provides a high level of development and understanding of the fuel performance and behavior. Most of the experience base with U-Zr binary is with enriched uranium feedstock.

Recent ABR reactor studies have been completed indicating that a low-enriched ( $18 \%)$ binary metal fuel core could be used for the startup fuel. Binary metal alloy fuel has a higher fuel smear density that UOx fuel and hence the reactor design studies indicate that this core could be as small as $800 \mathrm{MWth}$ under this option (Kim et al. 2008).

\section{$4.3 \mathrm{U}-\mathrm{Pu}-\mathrm{Zr}$}

Similar to MOX fast reactor fuel, U-Pu-Zr ternary fuel also has a proven fabrication and irradiation database from the EBR-II and Fast Flux Test Facility (FFTF) reactor programs. Near the end of the FFTF reactor program it was qualified to the extent that the FFTF was to be converted from MOX driver fuel to $\mathrm{U}-\mathrm{Pu}-\mathrm{Zr}$ driver fuel in the MFF test series. The use of this fuel for the startup fuel of the ABR is that most of the historical basis for U-Pu-Zr is using the RG isotopic feed stream. Domestic acquisition of a $\mathrm{U}-\mathrm{Pu}-\mathrm{Zr}$ startup fuel would most certainly require the use of WG feedstocks.

\subsection{Enriched $\mathrm{UO}_{\mathrm{x}}$}

One of the simplest and in some respects the most effective means to obtaining a startup fuel is to use a UOx fuel composition with U235 enrichment above 20\%. This type of fuel has an extensive fabrication history, irradiation experience base, and facilities currently available to support fabrication. The flexibility of enrichment and fabrication variables allows for a very flexible reactor core design. The possible negative aspect of this option is the political desire to minimize the use of HEU in a new reactor design. 
Recent ABR reactor studies have indicated that it may be possible from a core and reactor design perspective to utilize $\sim 18 \%$ U235 enriched oxide fuel for the ABR startup core. These studies indicate that this option demands a reactor core having a size $>1000$ MWth. (Kim et al. 2008)

\section{FUEL FABRICATION FACILITY OPTIONS}

\subsection{Domestic US Facilities and Capabilities}

In this section, domestic fabrication capabilities are reviewed.

\subsubsection{Nuclear Fuel Services (Erwin, TN)}

Nuclear Fuel Services (NFS) was established in 1957 and continues business today as a small business enterprise. Nuclear Fuel Services operates under a Nuclear Regulatory Commission Category 1 fuel fabrication license. This license allows the handling, use, and production of nuclear fuels having greater than $20 \%$ U235 enrichment. It was originally established by W. R. Grace as a nuclear component supplier to the developing United States commercial nuclear industry.

In the 1960s, NFS started supplying HEU fuel to the U.S. Department of Energy. Over the past 10 years, NFS has applied its HEU expertise to several HEU recovery and downblending projects. Nuclear Fuel Services downblends HEU to low-enriched uranyl nitrate solution, which is converted to $\mathrm{LEUO}_{2}$ powder at the Erwin site and further processed into commercial nuclear fuel by NFS's partner, AREVA. This experience provides a robust infrastructure for handling a variety of HEU materials, as well as HEU technical processing know-how unparalleled in the nuclear industry. Nuclear Fuel Services has successfully applied continuous improvement programs driven by Lean Six Sigma and Value Stream Mapping protocols to achieve dramatic improvement in throughput and quality of product. The nature of its business demands a strong safety culture in manufacturing.

As a licensed Category I processing facility, NFS owns and operates the facilities and systems to receive, store, track, handle, process, and ship nuclear materials of all enrichments. Nuclear Regulatory Commission License Special Nuclear Material (SNM)-124 permits NFS to receive, store, and process a wide variety of enriched uranium materials (up to $100 \% \mathrm{U}-235$ ) in a manner that provides maximum safety and compliance. In addition, NFS processes these materials to form final products that meet or exceed customer specifications for nuclear fuel applications. Nuclear Fuel Services successfully amended its NRC license to encompass four new facilities on its site within a four-year period. It is expected that HEU fuel fabrication for the Advanced Burner Reactor (ABR) would fit under the existing license.

In the 1970s, NFS designed, built, and operated a fuel production line to produce mixed oxide (plutonium oxide - uranium oxide) fuel for use in both thermal and fast reactors. Nuclear Fuel Services fabricated MOX fuel for a commercial light water reactor (LWR). Nuclear Fuel Services also manufactured the fuel for the Southwest Experimental Fast Oxide Reactor (SEFOR) reactor. The process used to make the fuel started with plutonium metal feed. The metal was converted to oxide powder, and the mixed uranium and plutonium oxides were processed into pellets. The finished products were welded fuel rods. Nuclear Fuel Services performed this work under its NRC license SNM-124, which was appropriately amended to address the safe handling of plutonium materials.

More recently, NFS designed a new fuel production line for uranium nitride fuel for the "Prometheus" space reactor project funded by the National Aeronautics and Space Administration (NASA). The NFS facilities were evaluated and plans were drafted to build the fabrication line to support this reactor development and construction project. NFS performed the preliminary design for the production line; it was estimated that a 10,000 sq. ft. fabrication and assembly capability was needed for the Prometheus 
effort. The production line for HEU fuel for the ABR would likely be of a similar scale. NFS can build a new facility of this size within its Category I fence.

A final important resource of NFS is its R\&D laboratories. NFS uses these facilities to not only improve current processes, but to validate new processes that will be installed within the plant. NFS can bench (and/or pilot) test a DOE fuel manufacturing flowsheet prior to final scaleup and implementation within the Erwin facility. The NFS analytical laboratories are also available to perform QC assays not only on test material, but also on final fuel product being shipped to the customer.

\subsubsection{Process Selection}

NFS has been involved in uranium unit processes for nearly 50 years with primary emphasis on chemical purification of the element and supply of specific uranium chemical compounds for use in fuel manufacture. They currently dissolve, purify, and downblend enriched $U$ from the weapons program. They were previously involved in the Prometheus Project for NASA and were setting up a fuel line to manufacture nitride fuel when that project was halted.

Nuclear Fuel Services does not have a line set up at this time to make either oxide pellet or metal fuel applicable to ABR startup fuel. They are currently setting up equipment for another program (required by June 2008) that would be fully usable to perform all feed conditioning processes needed to support fast reactor fuel manufacture. As part of the setup for the other effort, sufficient additional space in this Category 1 facility to install either an oxide or metal fuel line is also becoming available.

\subsubsection{NFS Approach to Provide Oxide Cores}

\section{Feed Conditioning}

For the manufacture of fuel for a fast reactor, NFS would need to use new feed conditioning capability currently being installed for another job (to be operational in June 2008). This new capability will be in one wing of the existing facility currently being used for downblending and uranium purification operations. The NFS experience in feed conditioning operations is extensive, and the new equipment being installed would be fully adequate for conditioning the feed materials for a fast reactor startup fuel.

\section{Fuel Formation}

Although NFS was previously involved in setup of a fuel line for the Prometheus Project, only a few miscellaneous equipment items (formation tooling and a sintering furnace) were received, and no installation was performed before the project was halted. Approximately 10,000 sq. $\mathrm{ft}$. of additional space will become available in the same facility wing that is being re-built to accept the feed conditioning equipment. NFS had expected to use that space to build a pilot scale fuel development facility. The space would be quite adequate for installation of the fuel formation and fuel encapsulation unit processes needed to meet the ABR startup fuel production requirements.

NFS presented the layout of a block flow diagram for the Prometheus Project which showed all the unit processes required for oxide fuel (plus the additional ones needed for nitride) that would be needed to make the ABR startup fuel. The NFS personnel appeared to have a reasonably good understanding of the steps involved in fuel pellet fabrication. In addition, they indicated that they would obtain the services of an oxide fuel formation consultant in order to effectively design, build, and operate the pellet formation portion of the fuel line.

\section{Fuel Encapsulation}

NFS appears to have minimal experience in the fuel encapsulation and core assembly aspects of the proposed ABR startup fuel fabrication. Although this end of the fuel manufacturing sequence is not 
considered especially technically challenging, external technology transfer assistance is expected to be required to put those unit processes into operation.

\section{Quality Control and Certification}

Quality control sampling and analysis is currently an unanswered question with NFS. The understanding is that those facilities are used to perform the needed QC analyses and tests to certify other nuclear products. As such, it is expected that they would be fully sufficient for ABR startup fuel needs. NFS personnel have expressed the ability to provide a listing of the existing QC equipment and analytical methods that would be available to support ABR startup fuel manufacture.

NFS has experience using both NQA-1 2000 and the Military Standard quality assurance programs in their operations.

\subsubsection{NFS Approach to Provide Metal Cores}

Because of their lack of experience with metal fuel manufacturing, NFS would be dependent on technology transfer from the national laboratories to set up and operate a metal fuel manufacturing line.

\subsubsection{Considerations on Nuclear Fuel Services as a Fabricator}

NFS has downblending expertise, but the scope of their fabrication activities cannot be disclosed. Although NFS does not have direct experience making the oxide pellets or metal casted fuel, their relatively complete flow diagrams, candid discussion of the process, and up-front admission about the need for additional technical assistance indicates a high probability of success. We believe the fabrication of the ABR startup fuel by NSF is a feasible option. Success at NFS would depend mostly on the assistance provided by the laboratory research infrastructure to help them set up the fast reactor fuel fabrication processes.

Overall, based on informal contact, NFS appears to be quite interested in this business and sees it as an excellent fit within their overall business plan. A formal cost and schedule assessment for the scope of desired support from NFS is needed to progress further.

\subsubsection{Babcock and Wilcox Nuclear Operations Group (Lynchburg, VA), formerly BWX Technologies (BWXT)}

Babcock and Wilcox Nuclear Operations Group (B\&W NOG) operates today as a small business enterprise in Lynchburg, VA. B\&W NOG designs and supplies components for United States government programs. The Lynchburg facility is one of only two U.S. facilities licensed to possess and process HEU. Along with its government work, the Lynchburg site is also home to Nuclear Operations Group's Uranium Processing and Research Reactors group (UPRR), which is skilled in both uranium downblending applications and plate-type reactor design and production for research purposes. B\&W NOG currently manufacture's the Idaho National Laboratory Advanced Test Reactor plate type fuel assemblies having greater than $20 \%$ enrichment in U235.

B\&W NOG operates under a Nuclear Regulatory Commission Category 1 license. This license allows the handling, use, and production of nuclear fuels having up to $100 \% \mathrm{U} 235$ enrichment. B\&W NOG has capabilities to support fabrication of startup fuel for a fast reactor.

Approximately 10 years ago, B\&W NOG operated a fuel production line producing Plutonium bearing mixed oxide fuel for the light water reactor industry. To do this, B\&W NOG had specific documentation and authorization from the NRC in approval of the documented safety assessment for the handling and production of $\mathrm{Pu}$ bearing fuel material. B\&W NOG abandoned this production line when the U.S. utility 
industry decided not to implement MOX bearing fuel in commercial reactors. The license authority from the NRC at B\&W NOG was also abandoned in order to pursue other product line priorities. B\&W NOG could handle Pu bearing material at its Lynchburg facilities following specific application and approval through the NRC.

\subsubsection{Process Selection}

B\&W NOG has a long history of fuel manufacturing, primarily for the Navy. Although B\&W NOG could theoretically manufacture either metal or oxide fuel, the metal fuel process is further outside their current experience base. B\&W NOG normally would purchase any required metal fuel materials in cast form from the Oak Ridge Y-12 operations.

\subsubsection{B\&W NOG Approach to Provide Oxide Cores}

\section{Feed Conditioning}

The B\&W NOG facilities that could be used for making the space reactor fuel currently include an extensive capability for $\mathrm{U}$ downblending, $\mathrm{U}$ purification (both centrifugal contactor and solvent extraction), chemical blending, and chemical treatment for co-precipitation and calcining. Their current development line capability beyond calcining is designed for sintering (reduction) of spherical particle fuel. A separate furnace would be required for reduction of $\mathrm{U}_{3} \mathrm{O}_{8}$ to $\mathrm{UO}_{2}$ as the existing fluidized bed furnace is inappropriate for treating fine powders.

Because of B\&W NOG 's experience in downblending and precipitation of oxides with appropriate properties for oxide fuel formation, they were confident that they could provide an oxide of an optimum particle size, stoichiometry, and surface area for direct use in pellet formation. Their proposed feed conditioning process would precipitate uranyl nitrate to ammonium diuranate (ADU) using ammonium hydroxide.

\section{Fuel Formation}

B\&W NOG does not have existing capability for fuel pellet formation. They would need to obtain a slugging press, granulator, pellet press, grinder, and sintering furnace at a minimum. Their stated approach would be to purchase a hydromet press that can be used both for slugging and final pellet formation. Their block flow for the process did not include any milling and grinding of feedstock on the assumption that it would not be necessary due to the quality of their conditioned feed. They did not show any step for binder or lubricant addition to the powder and indicated that they would prefer not to use additives or to minimize their use to the extent feasible. (NOTE: Unless the feed material has very high surface area leading to exceptional compaction and granulation properties, the assumption that binder and lubricant is not required is overly optimistic.) Most oxide processes use a starting powder with a stoichiometry above 2.0 and add scrap recycle streams to generate the blend actually used for pellet pressing. The B\&W NOG block flow did not show any recycle back to the front end and did not show any milling, grinding, or mixing unit processes. These process steps are known to be needed and will need to be included in any future assessment of cost, schedule, capability study.

\section{Fuel Encapsulation}

The fuel encapsulation process steps were termed "labor intensive" but B\&W NOG did not indicate that significant new purchased equipment would be required. No encapsulation equipment, however, was shown on the tour. Although it is expected that equipment usable for encapsulation does exist in other fuel lines it is still unclear how such equipment might be shared, what modifications would be required, and how sharing might affect production timing. 


\section{Quality Control and Certification}

There is no doubt that B\&W NOG has the capability to perform the QC and certification required for fuel powders and finished fuel rods, although their QC and inspection labs were not toured as part of this trip (this author has seen them previously). As indicated in the meeting, it would be appropriate to purchase equipment for dimensional and visual inspection of fuel pellets after grinding, although even this work could be done manually. B\&W NOG is an approved supplier for NQA-1 fuel products (ATR fuel and Advanced Gas Reactors [AGR] fuel), but as a new project the B\&W NOG quality manual would require modification to include the project, and QA audits would be required to establish the adequacy of the procedures specifically employed for this new activity.

\subsubsection{BWX Approach to Provide Metal Cores}

Because of their lack of experience with metal fuel manufacturing, B\&W NOG would be dependent on National Laboratory technology transfer to set up and operate a metal fuel manufacturing line.

\subsubsection{Considerations on B\&W NOG as a Fabricator}

Although B\&W NOG is not currently involved in making oxide pellet fuels, their background and experience in fuel manufacturing is extensive with production lines to make Naval Reactor fuels, ATR test reactor fuel, High-Flux Isotope Reactor (HFIR) test reactor fuel, and test particle fuels for Advanced Gas Reactors. The former Babcock and Wilcox was a commercial oxide pellet fuel manufacturer, but that specific expertise has not been retained at B\&W NOG. It is expected that B\&W NOG would be successful in manufacturing GNEP ABR startup fuel but they will need some outside technical assistance and potentially additional time to get to full production due to the learning curve involved. The $\mathrm{B} \& \mathrm{~W}$ NOG facility space was at a premium, but it is expected that they could convert an existing storage space in one part of their development facility to be used for the required fuel line processes. A formal cost and schedule assessment for the scope of desire support from B\&W NOG is needed to progress further.

\subsubsection{Los Alamos National Laboratory - PF-4}

In 2007, the Los Alamos National Laboratory was assigned to look at the feasibility of producing a MOX (mixed uranium and plutonium oxide fuel) startup core for the GNEP ABR at the Plutonium Facility (TA-55, PF-4). Merrick \& Company, an architectural and engineering firm, was contracted for performing the study. Merrick subcontracted to Smith Concepts \& Designs, to perform the baseline process flow, capability design, and construction schedule estimate. Smith Concepts also performed an analysis for an annual MOX fabrication rate and $\operatorname{cost}^{\mathrm{a}}$. A second subcontractor, Q-Consulting, provided a construction cost estimate based on the design build, and install schedule ${ }^{\mathrm{b}}$. The basis for the fuel capability design was traditional MOX fabrication and the FFTF MOX specification ${ }^{\mathrm{c}}$. The study was based on several assumptions; plutonium oxide feed powder meeting specification is supplied from an outside source and the work is in a Category I Nuclear Facility. Other considerations taken into account are worker ALARA (As Low As Reasonably Achievable) radiation exposure and laboratory ergonomic goals. This study specifically looked at the configuration and costs for one room and a portion of a second room in PF-4. Related infrastructure costs were not investigated in this study, such as vault operations, storage of fuel pins, packaging and transportation, etc. In addition, the fabrication process ended with fuel pin assembly, with no fabrication of core assemblies. Some alternative processing techniques were identified during the feasibility study to increase production rates, but would require further evaluation.

\footnotetext{
a. Feasibility Study for Advanced Burner Reactor Fuel MOX Fabrication, awaiting LA-CP-07-XXXX, Sept 2007.

b. ABR Driver Fuel Assessment, LA-CP-07-XXXX, Sept 2007.

c. Fast Breeder Reactor Oxide Fuel Pellet, NE 13-6T, January 1984.
} 
The facility layout to support the MOX fabrication and fuel pin assembly used the majority of two standard rooms in PF-4. The Actinide Ceramic and Fuel Team currently occupies two rooms. A portion of the second room is being used to preserve a nuclear fuel $\mathrm{R} \& \mathrm{D}$ capability. This room configuration requires the larger equipment be placed in the middle of the room, to accommodate the doublewide glove boxes. This results in a somewhat inefficient process layout. If a doublewide room in PF-4 were utilized, this would support a more efficient process layout, because there is greater flexibility in placement of the doublewide glove boxes. The study began with the R\&D MOX fabrication process from PF-4, and then looked at incorporating fabrication techniques that support larger scale fabrication. Some of these alternative processing techniques will need to be evaluated before being incorporated into a construction design. This detailed analysis resulted in equipment and glove box models, which were used to support the cost and schedule estimates.

Table 3 shows the design and construction schedule covered all the major steps to establish a capability, including engineering and design, equipment fabrication, facility preparation, glove box installation, facility systems, installation qualification, authorization basis, and production set-up and qualification of the fuel line. The total schedule for these activities was 5.5 years for design and construction and 1.5 years for fabrication qualification. Engineering and design was three years in order to test out new concepts for streamlining the process and to develop a robust design. The schedule could be shortened by beginning to evaluate new concepts now with fuel development money. The construction phase, including installation qualification was 2.5 years; this assumes glove boxes and equipment are built and tested outside, then moved into PF-4 and connected to facility utilities. Authorization basis work is intermittent and ongoing from near the beginning of the project through the operational readiness assessment. MOX fabrication qualification is scheduled for 1.5 years. Many of the schedule activities are overlapping and not in series. The conceptual design included equipment selection, material transport, and specific glove box designs for the process. This generated detailed equipment lists, thus supporting the schedule and cost analysis.

The cost estimate was based on the schedule and quotes from glove box and equipment manufacturers. The cost estimate, based on FY-07 dollars, included a 14\% escalation factor to coincide with the start of construction. The construction costs covered equipment fabrication through installation qualification. The cost ranged from a low of $\$ 102 \mathrm{M}$ to a high of $\$ 168 \mathrm{M}$, with an accuracy of $-10 \%$ to $40 \%$. Project cost contingency of $40 \%$ is included in these costs. This also includes glove box defueling and decommissioning (D\&D) costs, which are highly variable. MOX Fabrication Set-up and Qualification were not covered in the cost analysis. Typically, programmatic operating funding is used for fabrication startup and qualification.

An annual fuel fabrication rate was calculated for the feasibility study, because the core is undefined. This throughput study used the PF-4 workweek schedule of four, 10-hour days per week, and assumed 70\% plant availability. The fuel fabrication schedule has two fuel batches starting per day, with six per week. It takes five working days to produce a $10-\mathrm{kg}$ batch of fuel. The steady state process throughput analysis to produce pellets $\sim 0.5 \mathrm{~cm}$ in diameter and $0.6 \mathrm{~cm}$ long yielded an annual production rate of $2,000 \mathrm{~kg}$ ( $2 \mathrm{MT}$ ) equating to $\sim 50 \mathrm{~K}$ pellets/week or $1.8 \mathrm{M} / \mathrm{yr}$. The $100 \%$ pellet inspection was the rate limiting factor in production followed closely by centerless grinding capacity. Production costs were estimated at $\$ 15 \mathrm{M}$ annually. 
Table 3. Capability Schedule Including MOX Fabrication Startup

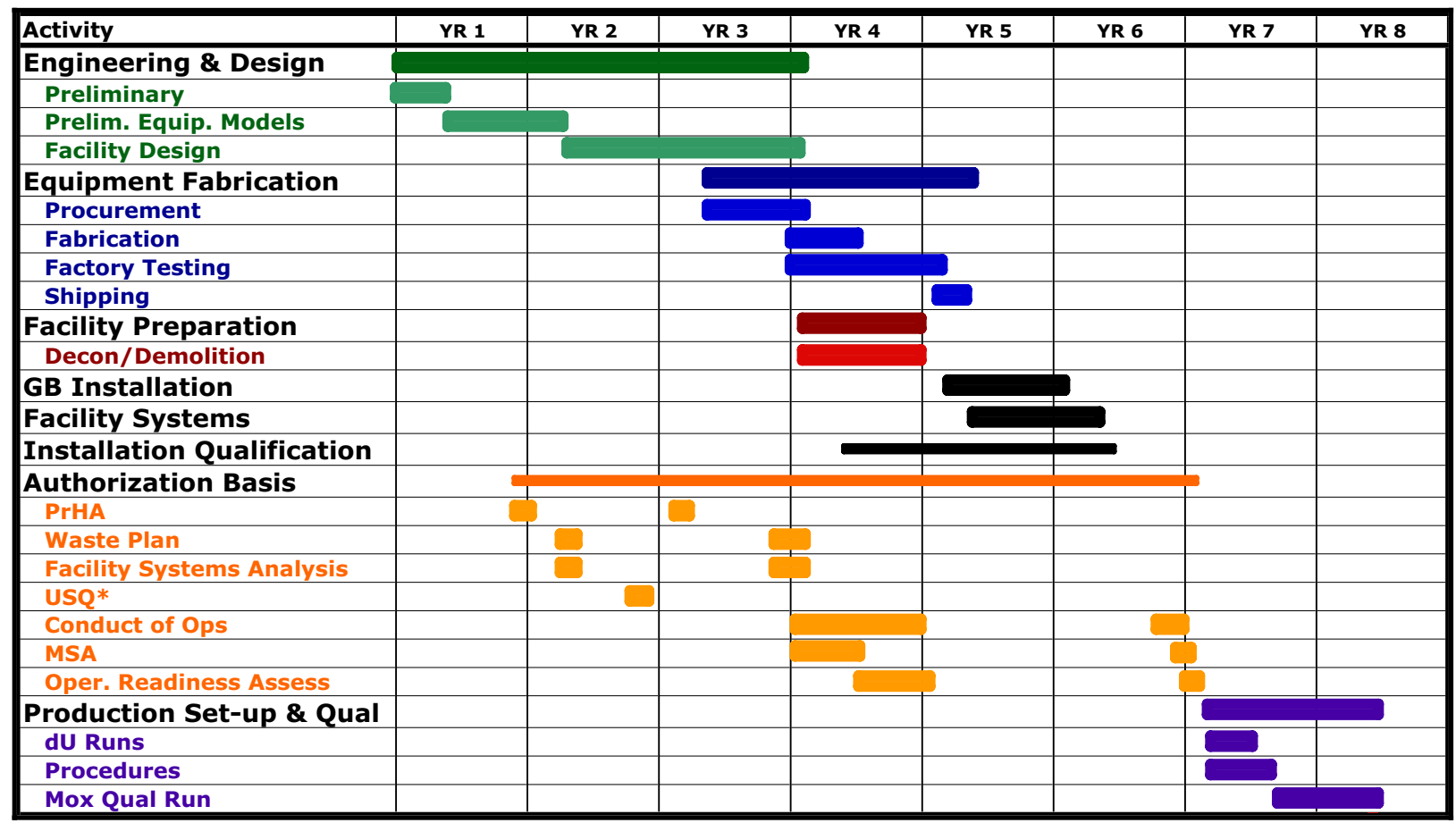

\subsubsection{Idaho National Laboratory - FMF}

In FY-07, the INL evaluated the facility costs and requirements for fabricating a startup metallic fuel core and subsequent replacements for the ABR demonstrator unit. For a metal fuel fabrication facility sited at the Materials and Fuels Complex (MFC) at the INL, the cost of construction of and the process equipment for the facility was estimated to be approximately $\$ 80 \mathrm{M}$; for a facility with an integrated capability for gallium contaminant removal from the feed stock, the estimated cost is $\$ 116 \mathrm{M}$.

The following information provides the assumptions used in doing the study. The ABR startup core composition will probably consist of plutonium, DU and zirconium. For a metal fuel core, that composition will probably be $75 \mathrm{wt} \% \mathrm{DU}, 15 \mathrm{wt} \% \mathrm{Pu}$, and $10 \mathrm{wt} \% \mathrm{Zr}$, with the plutonium feedstock consisting of weapons grade $\mathrm{Pu}$. For the metal fuel, the fuel pins will be approximately $14.5 \mathrm{ft}$ long, bundled to make fuel assemblies with 217 fuel pins, in which the fuel stack is approximately $81 \mathrm{~cm}$ long.

The fuel fabrication facility must be able to produce 45 startup fuel assemblies per year, with an output of 4 metric tons of heavy metal $(>580 \mathrm{~kg} \mathrm{Pu})$ per year. The flowsheets for the fuel fabrication process are given in Appendix A, and the flowsheets for the process including gallium removal process are given in Appendix B. The production of metal fuel involves the head-end processing of metal feed stock components, induction melting, casting, and finishing of fuel rodlets of the required metal composition; loading of the fuel rodlets in the cladding containing sodium metal; seal welding the fueled sections; forming the sodium metal bond between the fuel rodlets and the cladding; and assembling the fuel pins and the fuel assemblies. All operations prior to sodium bonding must be performed under inert gas (argon) in a glove box. Because of criticality limits to batch sizes in the process, the facility requires at least two parallel metal processing lines to meet the facility output requirement. In addition, the facility must also contain a secure vault to store at least a one-year supply of Pu feedstock and 45 finished fuel assemblies, as well as the casting heels and off-specification product from the process that will be recycled. Finally, because of the quantity of $\mathrm{Pu}$ that would be in process and storage, the facility must conform to Category I facility security requirements. 
While the INL has two Category I facilities (the FMF and the Zero Power Plutonium Reactor [ZPPR] complex at the MFC), both are expected to be dedicated to other projects, and neither is large enough to accommodate the required process lines and storage requirements. Therefore, two construction options were evaluated: an annex to the FMF, and a stand-alone facility attached to the FMF. The designated location offers a suitable undeveloped area close to the existing underground utility feeds for FMF, clustering with the high-security FMF and ZPPR Category I facilities, and an existing dual-fence security perimeter surrounding the FMF-ZPPR complex.

An architectural engineering consortium, headed by ANNA, Inc., and including Burns and Roe and Vista Engineering Technologies, LLC, was contracted for the pre-conceptual design and cost estimates. With INL participation, ANNA, Inc., developed the Technical and Functional Requirements for the fabrication facility, a facility Options Analysis (annex to FMF vs. a stand-alone facility, and an integrated vs. separate gallium removal facility), the pre-conceptual design for the preferred option, and the cost estimates for construction and process equipment. The results of these tasks were documented in a report by ANNA, Inc. (see Reference 20).

The Options Analysis clearly favored a stand-alone facility over an annex to FMF. The FMF annex option required the removal of a portion of the existing FMF security barrier (berm) and breaching of an exterior wall to the facility. These activities would have required the relocation of the special nuclear materials stored in FMF to the ZPPR facility, also a Category I facility; however, the ZPPR storage space was inadequate for the FMF inventory. There was no other place to relocate the materials. The preferred option is therefore a stand-alone facility located just east of FMF, within the PIDAS security fences. The proposed facility is a single-story 24,000 sq. ft. building (approximately $220 \mathrm{ft}$ by $145 \mathrm{ft}$ ), and would house the metal fuel fabrication lines (metal fuel rodlet fabrication, fuel pin fabrication, fuel assembly fabrication), storage vault, truck bay with shipping and receiving area, and support and administrative offices the estimated cost for the construction of the facility is approximately $\$ 80 \mathrm{M}$; the estimated cost includes the design, procurement, and installation of the associated process equipment, including glove boxes (approximately $\$ 30 \mathrm{M}$ ). The cost estimate includes a 15\% contingency for the process equipment and a 30\% contingency for construction. The yearly operation cost was not specifically studied in this cost and schedule effort, but it is expected that based on past EBR-II fabrication experience that approximately 45 FTEs will be needed to support the production rate. This is also similar to the cost of yearly operation of the PF-4 facility.

The integration of the ability to remove gallium contamination from the $\mathrm{Pu}$ feed stock requires a 34,000 sq. ft. facility that includes a partial basement and a partial second floor to accommodate to gallium separation lines, feed stock tanks, acid recycling, and a waste storage tank. The construction cost estimate for a fabrication facility with gallium removal capability is $\$ 116 \mathrm{M}$; the cost estimate includes the design, procurement, and installation of the associated process and separations equipment (approximately $\$ 56 \mathrm{M})$, with the same contingencies.

Note that the option with and without the gallium removal capability were both evaluated in this study. However, gallium removal (if it were needed) would be preferable at the origin of the Pu shipment, as the $\mathrm{Pu}$ materials would likely have to be processed before shipment to eliminate or transform restricted 'signatures' of the materials (geometric and chemical). Moreover, the need for gallium removal is not certain. A U-Pu-Zr metal fuel test in EBR-II using weapons grade Pu with Ga had no performance problems, although the program ended before the experiment achieved sufficient fuel burnup to clearly demonstrate this to high exposure.

\subsubsection{SRS MD-MOX Plant (Under Construction)}

Currently, the National Nuclear Security Administration (NNSA) Surplus Weapons Plutonium Disposition Program is in the process of constructing a light water reactor MOXFFF at SRS. This plant is 
currently designed to fabricate weapons grade MOX fuel for light water reactors (typically in the 5 to $6 \%$ $\mathrm{Pu}$ range). It is conceivable that this plant could be converted to produce higher concentration $(20-25 \%$ $\mathrm{Pu}$ ) fuel compositions. This would require a detailed, specific design study.

Initial discussions have been held between DOE and NNSA regarding the capabilities of this facility and the changes that would be required to convert the plant to fabricate ABR fuels. It was concluded that the most significant impacts of the conversion would be on criticality safety following the primary blending operation, worker dose, heat generation in the latter stages of the fuel fabrication process, and storage and transportation. Most of these effects could be offset by facility design changes. It was assumed that the mission to fabricate ABR startup fuel would not begin until the current plutonium disposition mission is completed in approximately 2030. This assumption is based upon the need to prevent cross-contamination of LWR and ABR fuel materials and the need to make significant modifications to the design of the facility to accommodate the higher plutonium content of the ABR fuel. A rough, preliminary estimate of the cost and schedule for facility conversion was $\$ 165 \mathrm{M}$ to $\$ 200 \mathrm{M}$, with two years of facility downtime.

\subsection{International Facilities}

There is a possibility that startup fuel for a U.S. ABR could be fabricated in an international facility. Three facility possibilities exist, Japan PFPF, Russia PO-Mayak, and CEA-LEFCA. These facilities currently have operating oxide fuel fabrication activities for fast reactors. No formal estimates have been generated from these options due to the current status of international agreements. Formal engagement will be required for proper cost and schedule estimate. Table 4 provides a summary of the capability and issues associated with the major international startup fuel fabrication facilities. The following sections provide more detail of each facility.

Table 4. Summary of potential international startup fuel fabrication facilities.

\begin{tabular}{|l|l|l|l|l|}
\hline $\begin{array}{c}\text { Fabrication } \\
\text { Facility }\end{array}$ & $\begin{array}{c}\text { Currently being } \\
\text { used for fast } \\
\text { reactor fuel } \\
\text { fabrication? }\end{array}$ & Fuel Type & \multicolumn{1}{c|}{$\begin{array}{c}\text { Current } \\
\text { Throughput }\end{array}$} & $\begin{array}{c}\text { Barriers to Future Use } \\
\text { (through 2020) }\end{array}$ \\
\hline Japan PFPF & $\begin{array}{l}\text { Yes, for Monju } \\
\text { and JOYO }\end{array}$ & Oxide pellet & $\sim 4$ MT/year & $\begin{array}{l}\text { Currently at capacity. } \\
\text { Expansion is not possible } \\
\text { without significant seismic } \\
\text { upgrading of the facility. }\end{array}$ \\
\hline $\begin{array}{l}\text { Russia }- \text { PO } \\
\text { Mayak }\end{array}$ & Yes, for BN-600 & Oxide pellet & $\begin{array}{l}40 \\
\text { assemblies/year }\end{array}$ & $\begin{array}{l}\text { None known other than } \\
\text { agreements. }\end{array}$ \\
\hline $\begin{array}{l}\text { France } \\
\text { LEFCA }\end{array}$ & Yes & $\begin{array}{l}\text { Oxide and } \\
\text { ceramic } \\
\text { nitride }\end{array}$ & $\begin{array}{l}<250 \mathrm{~kg} / \mathrm{year}- \\
\text { estimate based on } \\
\text { relative size. }\end{array}$ & $\begin{array}{l}\text { Cannot support larger } \\
\text { throughput }- \text { research } \\
\text { quantities only. }\end{array}$ \\
\hline
\end{tabular}

\subsubsection{CEA/Cadarache LEFCA MOX Fuel Line}

CEA currently operates a small MOX fuel fabrication line at the Cadarache site in the LEICA facility. This line is relatively small and is currently used to fabricate test quantities of fuels for the Phenix reactor. The much larger fabrication facility located next to the LEICA facility has been closed. It was previously operated by the Compagnie Generale des Matieres Nucleares (COGEMA) corporation and produced driver fuel for both the Phenix test reactor and the commercial fast reactor demonstration plant Superphenix. Superphenix is in a decommissioned state and Phenix is scheduled for shutdown in mid-2009. CEA's fabrication capabilities for fast reactor MOX fuel are currently in the same state as the United States'. Based on private communication with counterparts in CEA, it is expected that there is 
opportunity to establish collaborative startup fuel fabrication facility support as CEA has stated plans to build a new ABR like fast reactor in the 2020 timeframe.

\subsubsection{Japan PFPF}

The Plutonium Fabrication Facility (PFF) located at Tokai, Japan and operated by the JAEA has manufactured plutonium bearing MOX fuel since the mid-1960's. Currently, the facility is fabricating fast reactor MOX fuel using reactor grade plutonium to be used as driver fuel in the Monju fast reactor. The PFF also manufactures fast reactor fuel for the JOYO test reactor. The facility is at capacity and can not supply fuel to both reactors at the same time. It is a possibility that the facility could manufacture startup fuel for a U.S. ABR but this would be very difficult if not impossible to negotiate with the JAEA. Similar to CEA, based on private communication with counterparts in CEA, it is expected that there is opportunity to establish collaborative startup fuel fabrication facility support as CEA has stated plans to build a new ABR like fast reactor in the 2020 timeframe. This would require JAEA to expand their fabrication capability.

\subsubsection{Russia}

There are facilities available in Russia for the fabrication of fast reactor MOX fuel. Currently the RIAR facilities have experience fabricating vibropac MOX fuel for the BOR-60 fast test reactor and the driver fuel for the BN-600 demonstration fast reactor is fabricated at the PO-Mayak site.

As of April 2001, Russia has no industrial-scale MOX fuel fabrication plant but does have one pilot plant, the Paket plant, which is able to produce small batches of MOX. The Granat plant, another small pilot plant that produced MOX, was shut down in 1997 for safety reasons and as of April 2001 remains closed. The Paket and Granat plants are located at PO Mayak in Ozersk and are designed to work with weapons-grade plutonium and produce MOX fuel for fast reactors. Construction of the Paket plant began in 1980 and was completed in 1993. Paket has the capacity to produce up to 40 MOX fuel assemblies per year.

Construction of Complex 300, a facility designed to produce up to 900 fuel assemblies for fast reactors, began in 1984 at Mayak, but was stopped in 1989 due to financial problems and delays in construction of the BN-800 fast reactors at Beloyarsk and South Urals NPPs. It seems unlikely that Complex 300 will be completed. Minatom has looked at other alternatives such as building a new MOX fabrication facility or importing an unused MOX facility from Germany.

Two pilot plants for MOX fuel fabrication exist in Russia: the Paket and Granat plants, both located at Mayak (Chelyabinsk-65). These two plants are designed to work with weapons-grade plutonium, and are designed to produce MOX fuel for fast reactors. Their capacity is not large-the maximum throughput of plutonium at the Granat plant is $50 \mathrm{~kg}$ per year (or one metric ton of MOX fuel) with a limited single loading of $300 \mathrm{~g}$ of plutonium. The capacity of the Paket plant is $100 \mathrm{~kg}$ of plutonium per year, or 30-36 fuel assemblies, which corresponds to one metric ton of MOX fuel with $20 \%$ plutonium content.

\subsubsection{Belgonucleaire}

Belgronucleaire has for many years fabricated light water reactor MOX fuel. The facility is not capable of fabricating fast reactor MOX fuel and in addition has been closed as of August 15, 2006.

\section{CONCLUSIONS AND RECOMMENDATIONS}

The capability exists in the United States to fabricate startup fuel for the GNEP ABR demonstration reactor, but a readily available facility of adequate size is not available. Choice of startup fuel supplier 
depends primarily on the choice of Pu-239 or U-235 as the fissile component of the fuel. Selection of metal or oxide as startup fuel does not make a difference in selection because the equipment needed for such a fabrication campaign will have to be built at any location chosen. If $\mathrm{Pu}-239$ is required for startup fuel, a reasonable choice for fabrication is either at the LANL PF-4 facility or at the INL FMF facility. If a low-enriched or HEU core can be utilized in the GNEP ABR, then a reasonable choice for fabrication might be at the NFS facility in Erwin, TN or the BWX NOG facility in Lynchburg, VA or a combination of the two.

Procurement from the commercial industry using the competitive bid process is recommended. It may be advisable to generate procurement documents designed to obtain proposals such that the Project retains options for splitting the fabrication into parts that can be awarded separately on the basis of cost or schedule.

The assessments conducted to date on US facilities indicates that if a reactor size greater than 250 MWth is selected, then startup fuel will be fabricated at multiple facilities will be required or a new large capacity fabrication facility will be needed.

The option exists to collaborate with international partners on joint a fuel fabrication facility. This option needs to be discussed further both in the GNEP program and with the potential international partners.

\section{REFERENCES}

1. Chang, Y. I., et al., 2006, "Advanced Burner Test Reactor Preconceptual Design Report," ANL-ABR-1 (ANL-AFCI-173), Argonne National Laboratory, Sept. 5, 2006.

2. Kim, T. K. and W. S. Yang, 2007, “A Metal Core Concepts for 1000 MWt Advanced Burner Reactor," ANL-AFCI-185, Argonne National Laboratory, April 20, 2007.

3. Kim, T. K. and W. S. Yang, 2007, "An Oxide Core Concepts for 1000 MWt Advanced Burner Reactor,” ANL-AFCI-185, Argonne National Laboratory, June 29, 2007.

4. Kim, T. K., W. S. Yang, and C. Grandy, 2008, "Core Concepts for a 2000 MWth Advanced Burner Reactor,” ANL-AFCI-217, Argonne National Laboratory, Jan. 15, 2008.

5. Badwan, F., et al., 1998, "Data Call for a Mixed Oxide Fuel Fabrication Facility Located at the Pantex Plant,” LA-UR-97-2067, Los Alamos National Laboratory, June 1998.

6. Bluhm, E. A., 2004, "Pu02 Polishing for MOX Fuel Fabrication-Process Modifications and Upgrades," LA-UR-04-3749, (Submitted to 28th Annual Actinide Separations Conference Asheville, NC), Los Alamos National Laboratory, June 2004.

7. DeMuth, S., 1997, "Conceptual Design for Separation of Plutonium and Gallium by Solvent by Solvent Extraction,” LA-UR-97-181, Los Alamos National Laboratory, April 1997.

8. DOE-9975, U. S. Department of Energy, Certificate of Compliance for Radioactive Material Packages - USA/9975/B(M)F-85 (DOE).

9. Hill, R. N., L. L .Briggs, et al., 2006, “Advanced Burner Test Reactor Startup Fuel Evaluation,"ANL-AFCI170, Argonne National Laboratory, June 30, 2006.

10. Hodge, S. A., and L. J. Ott, 2006, "Implications of the PIE Results for the 50-GWd/MT MOX Test Capsules," ORNL/TM-2006/83, UT-Battelle, LLC, Oak Ridge National Laboratory, May 2006.

11. Kim, T. K., and W. S. Yang, 2006, "Preliminary Estimation of Isotopic Inventories of $2000 \mathrm{MWt}$ ABR," Argonne National Laboratory, December 20, 2006. 
12. Kolman D. G., M. E. Griego, C. A. James, and D. P. Butt, 2000, "Thermally Induced Gallium Removal from Plutonium Dioxide for MOX Fuel Production," Journal of Nuclear Materials, $282245 \pm 254$.

13. O'Connor, D. G., et al., 1998a, "SRS MOX Fuel Lead Assemblies Data Report for the Surplus Plutonium Disposition Environmental Impact Statement," ORNL/TM-13483, Oak Ridge National Laboratory, August 1998.

14. O’Connor, D. G., et al., 1998b, "LLNL MOX Fuel lead Assemblies Data Report for the Surplus Plutonium Disposition Environmental Impact Statement," ORNL/TM-13480, Oak Ridge National Laboratory, August 1998.

15. ORNL, 1998, "Technical Report for Generic Site Add-On Facility for Plutonium Polishing Fissile Materials Disposition Program,” ORNL/TM-13662, Oak Ridge National Laboratory, June 1998.

16. Ott, L. J., S. A. Hodge, and R. N. Morris, 2005, "Weapons-Derived Mixed Oxide Fuel Test Irradiation Summary," ORNL/TM-2005/255, UT-Battelle, LLC, Oak Ridge National Laboratory, December 2005.

17. Sanzo, D., R. Erickson, and J. Ireland, 2006, "Initial Assessment of Plutonium Feeds Available for Global Nuclear Energy Partnership (GNEP) Activities,” LA-UR-06-7975, Los Alamos National Laboratory, July 2006.

18. Wilson, D. F., et al., 1997, "Interaction of Zircaloy Cladding with Gallium 1997 Status," ORNL/TM-13505, November 1997.

19. Khericha, S. T., 2007, "Preliminary Data Call Report Advanced Burner Reactor Start up Fuel Fabrication Facility," INL/EXT-07-12567, April 2007.

20. Porter, D. L. and M. A. Ebner, 2007, "Pre-Conceptual Design and Cost Estimate for an ABR Metal Fuel Fabrication Facility," Rev 0, INL/EXT-07-13216, GNEP-ABR-Fuel-TD-RP-2007-000338, September 20, 2007. 